\title{
المنظور المحاسبي لتفعيل ادوات العولمة عبر أليات معايير المحاسبة الاولية
}

\author{
أ. م. د. إبراهيم خليل حيدر السعدي

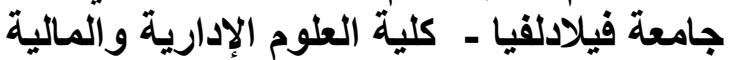 \\ قسم المحاسبة الإبة
}

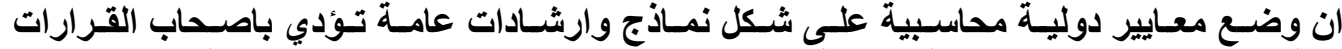

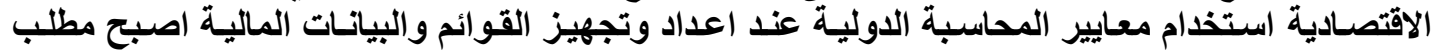

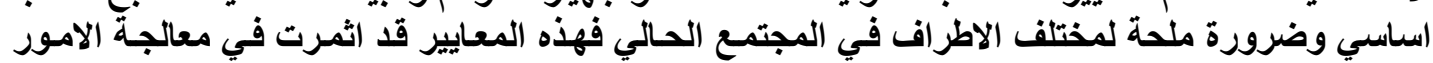

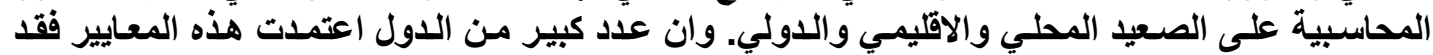

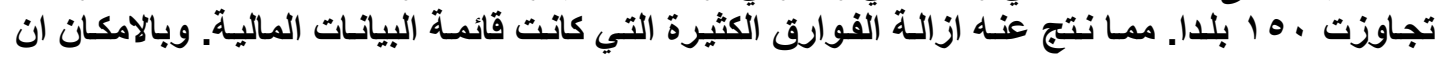

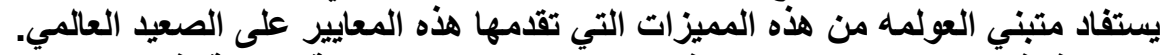

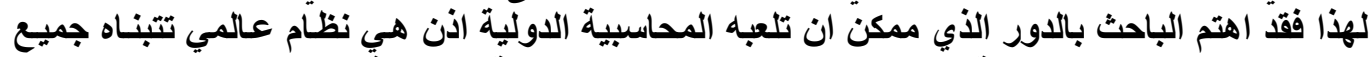

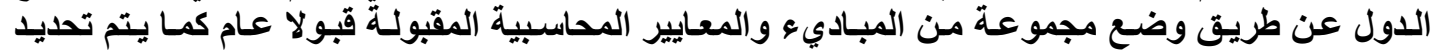

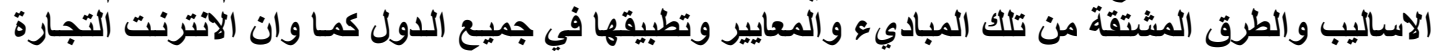

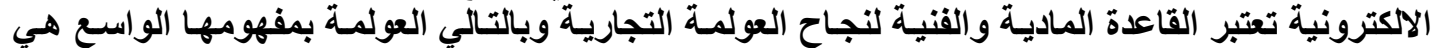

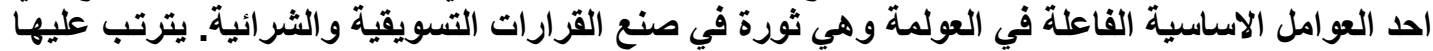

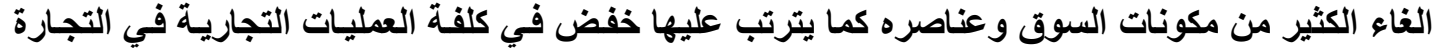

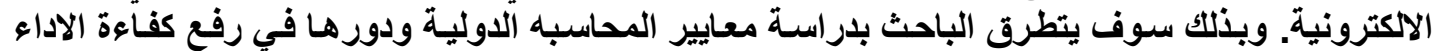

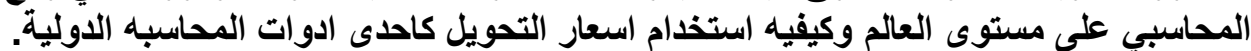

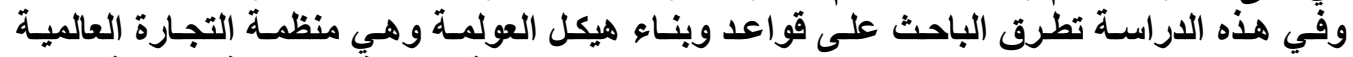

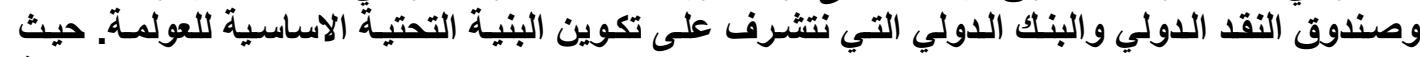

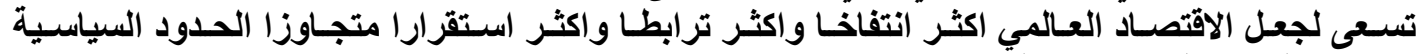

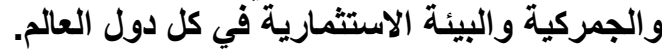

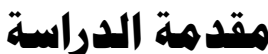

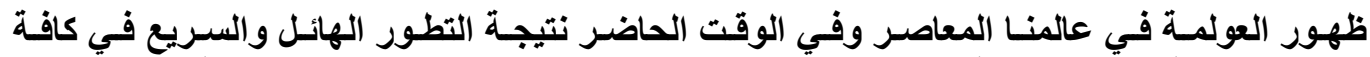

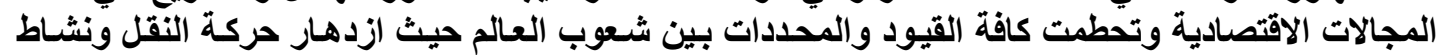

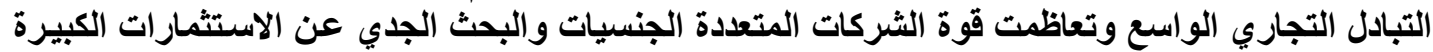

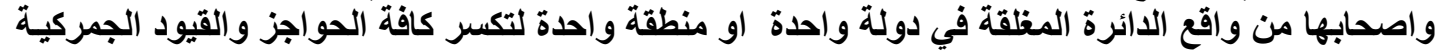

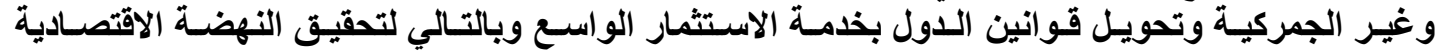

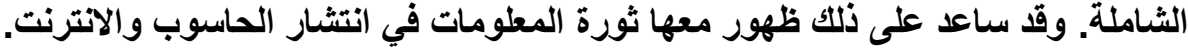

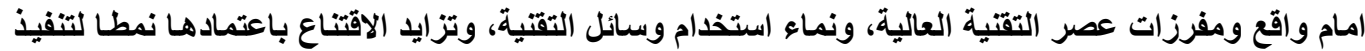

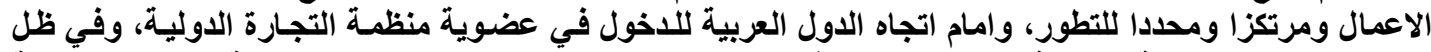

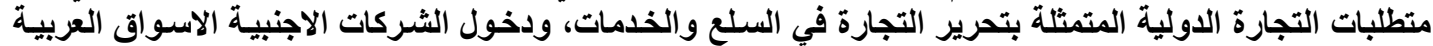

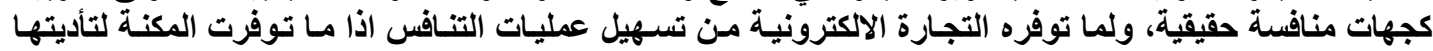

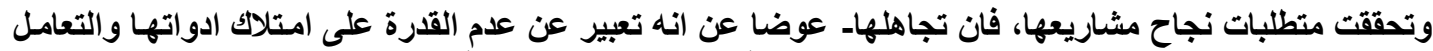

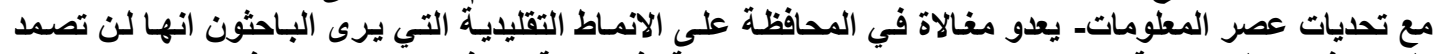

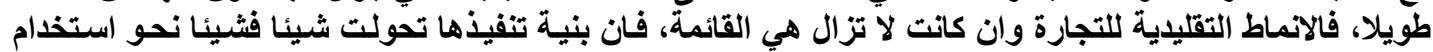

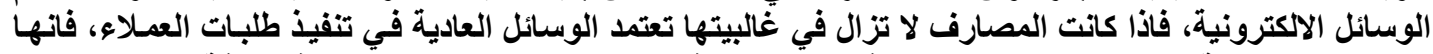

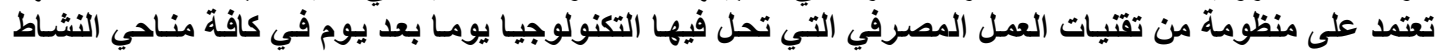

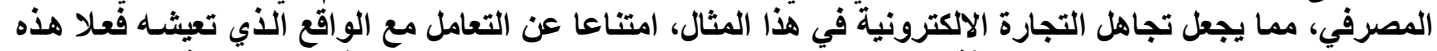

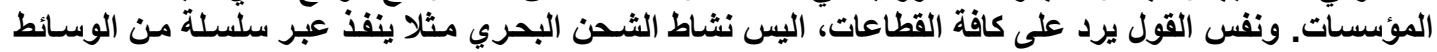

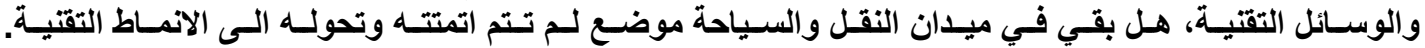




\section{طبيسمة الإشكاة}

هناك العديد من المشـاكل والصـوبات التي تواجـه ترجمـة العولمـة على المستوى المـالي والاقتصـادي

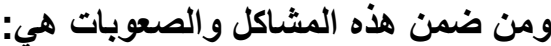
ا - مشـاكل قياس واعداد التقارير المحاسبية التي تنشأ نتيجة العمليـات التجاريـه الدوليه ونشـاط الثـركات

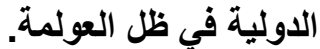
rـ التوحيد والتنسيق بين المبادى والتقارير المحاسبية المختلفة على مستوى العا لم عن طريق الانشطة

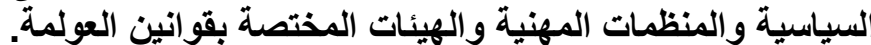

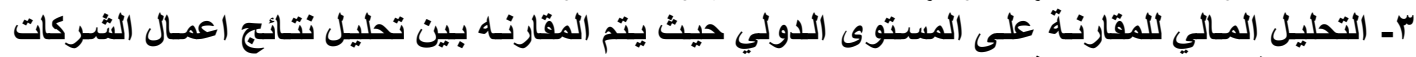
العامله في الدول المختلفة. ع - مشاكل توفير البيانات المحاسبية التى تحتاجها التجارة الاكترونية كاحدى قنوات العولمة.

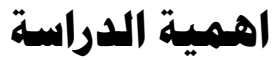

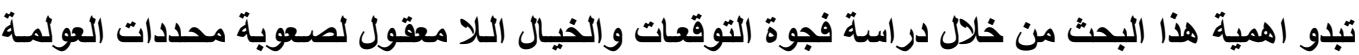

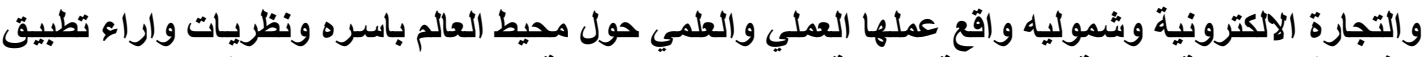

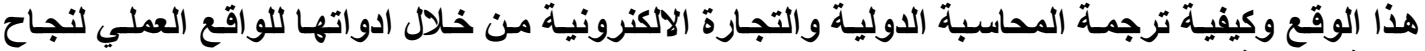
عملية العولمة.

\section{فرضيات الدراسة}

على ضوء التحليل الموضوعي لمتغيرات البحث ولمعرفة اثر المحاسبة الدولية والتجارة الاكترونية

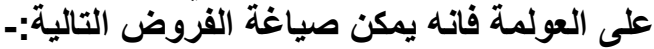

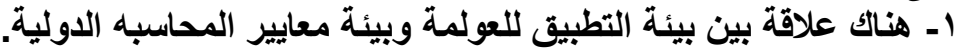

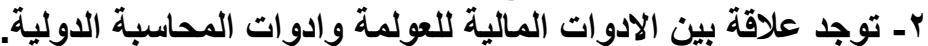

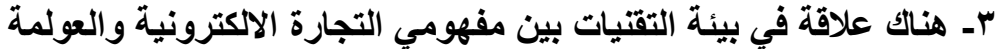

اهداف الدراسة هنية

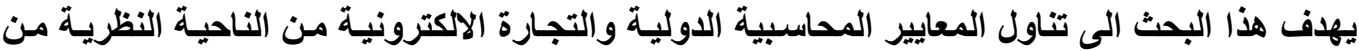

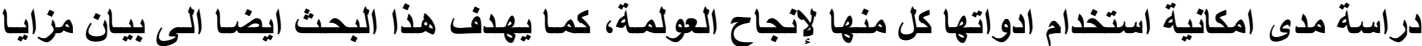

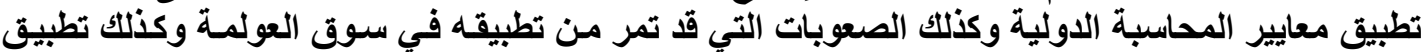

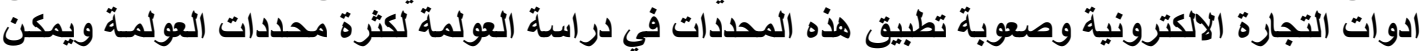
تحقيق هذه الاهداف من خلال المحاور التالية: التية:-

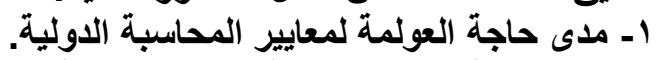

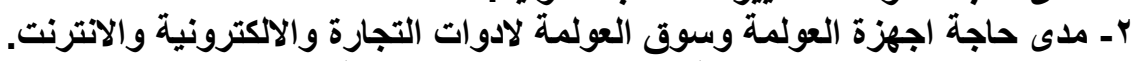

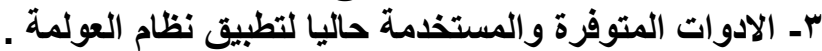

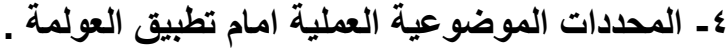

\section{هنهمية الدراسة}

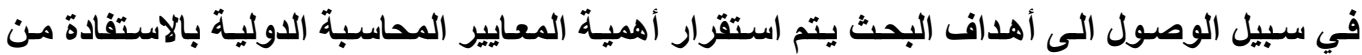

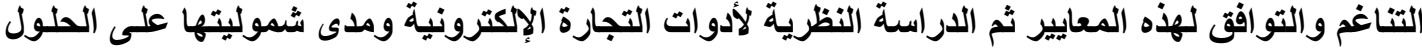

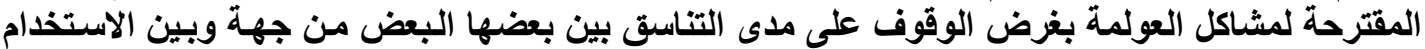

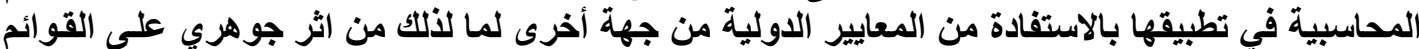

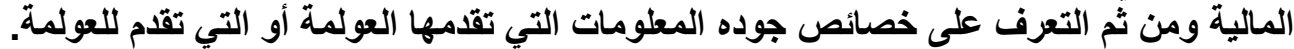

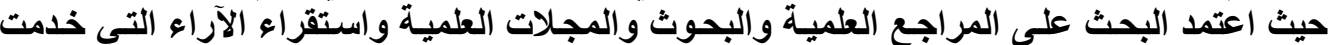
وسناعت على إنجاز البحث. 
خطة الدراسة

تم تقسيم البحث الى المحاور الرئيسية التالية:

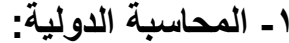

تعريفها- معايير المحاسبة الدولية ومدى الالتزام بها دوليا أسعار التحويل

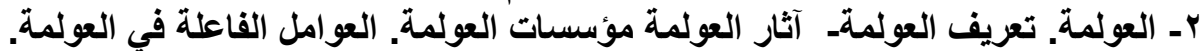

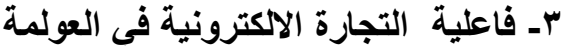

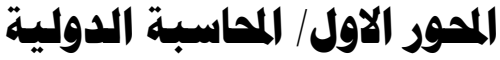

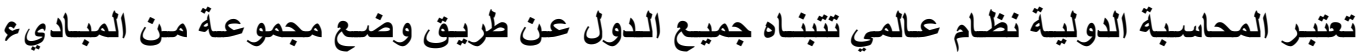

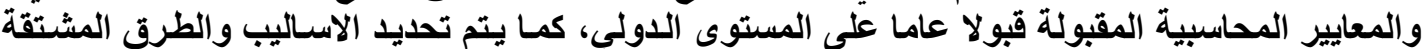

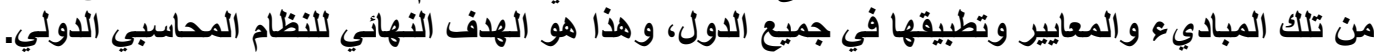

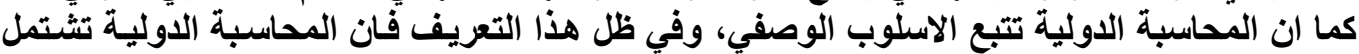

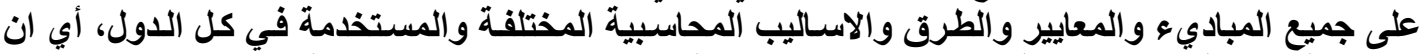

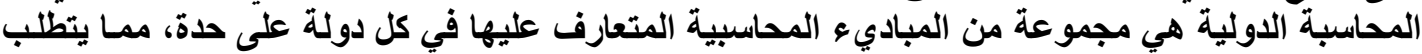

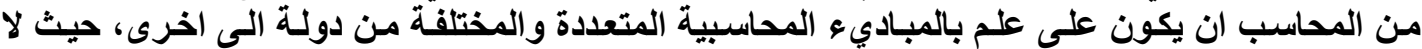

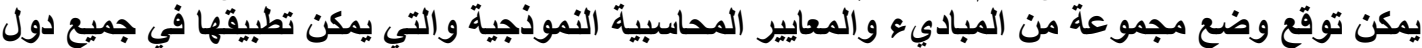

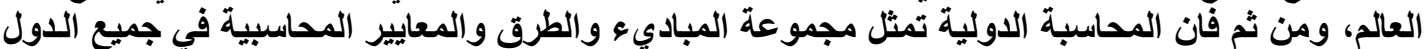

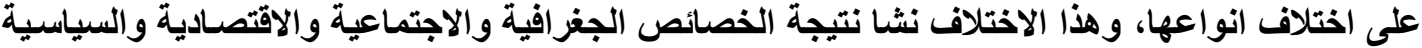

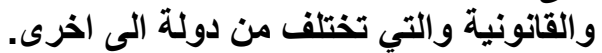

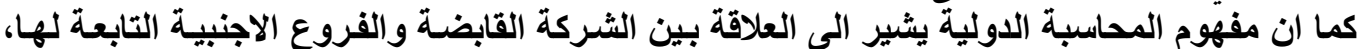

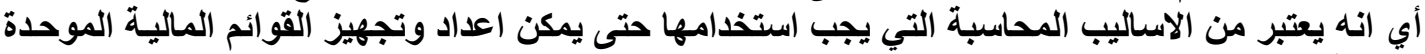

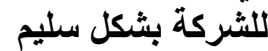

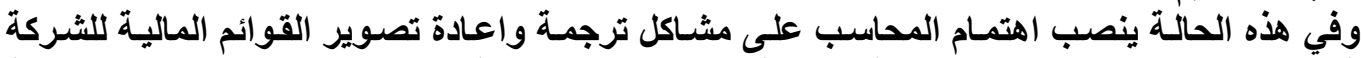

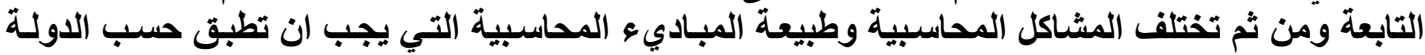

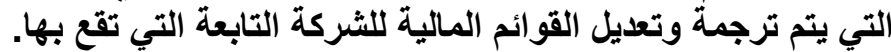
كما ان المحاسبة الدولية ما هي الا امتداد للمحاسبة المالية التية حيث ان التالية الاهداف العامة للمحاسبية يجب ان

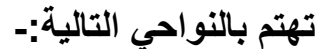
(أ) التحليل المالي للمقارنة على المستوى الدولي، حيث يتم المقارنـة بين تحليل نتائج اعمـال الثركات العاملة في الدول المختلفة. (ب) مشاكل قُياس واعداد التقارير المحاسبية التي تنشا نتيجة للعمليات التجارية الدولية ونشاط الثركات

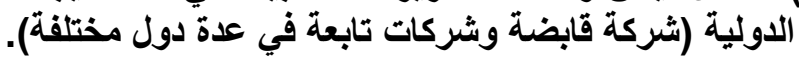

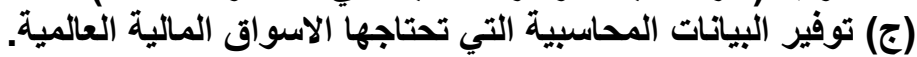

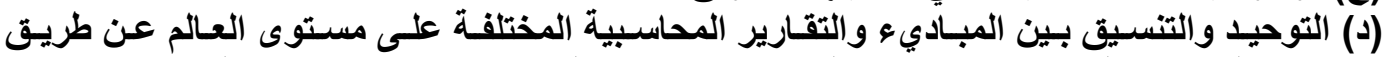
الانثطة السياسية، والمنظمات المهنية والهيئات المختصة بوضع المعايير المحاسبية.

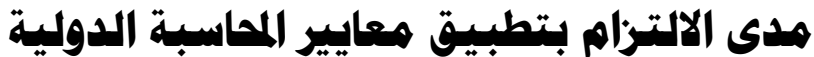

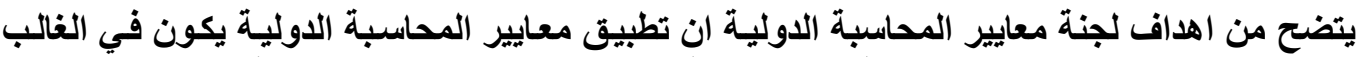

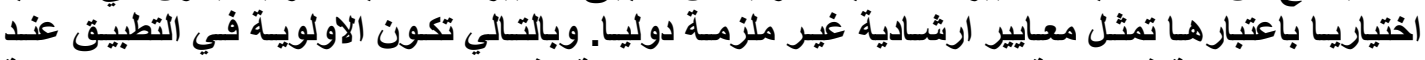

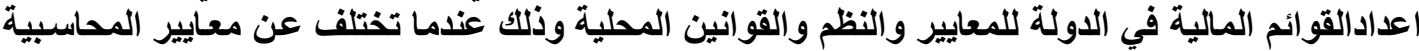

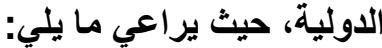
(أ) إذا كاتت المعايير المطبقة في القطر اقل من المعايير الأي اقرها الاتحاد الدولي تطبق معايير الاتحساد

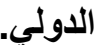
(ب) إذا كاتت المعايير المطبقة في القطر اكثر واشد قوة من المعايير المحاسبية الدولية تطبق معايير

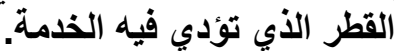
(ج) اذا كانت المعايير المطبقة في الدولة الام صالحة واقوى واشئ الثد صرامة من المعايير في القطر الذي تؤدي فيه الخدمة تطبق معاييز القطر الأم. 
ان عولمة المحاسبة يكون مفيدا من الناحية النظرية لان الواقع قد يتضمن انحرافا في مجال التطبيق

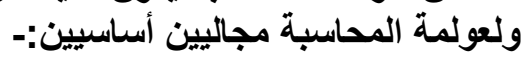

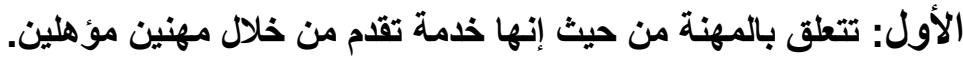

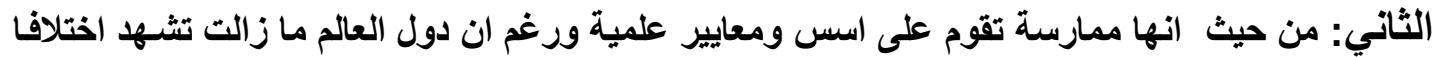

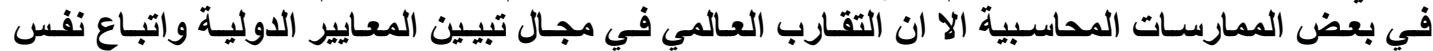
السياسات المحاسبية يتطور بشكل متسارع.

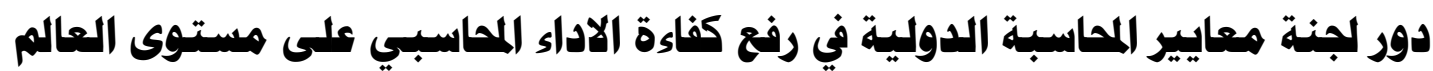

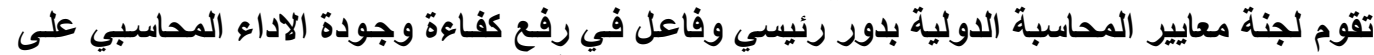

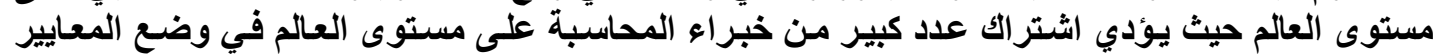

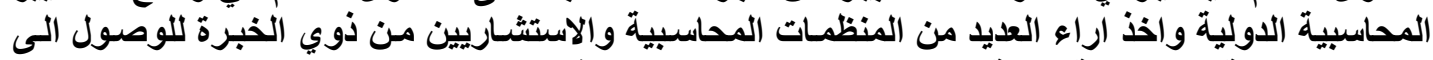

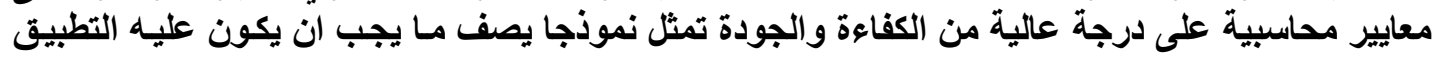

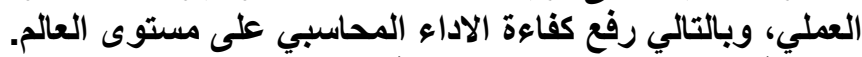

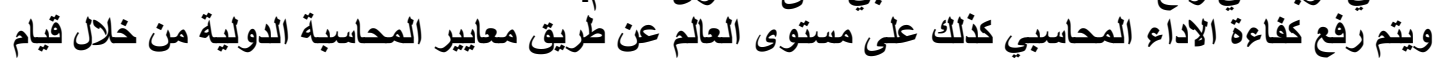

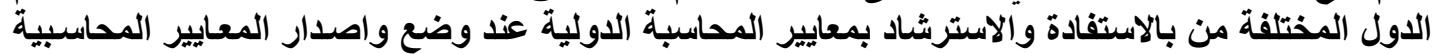

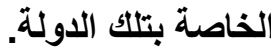

\section{تطبيق المعايير الدولية المانية}

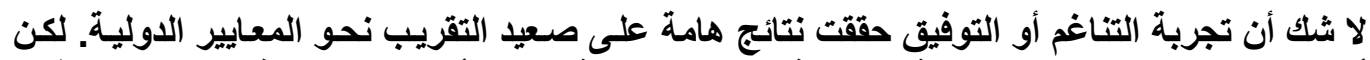

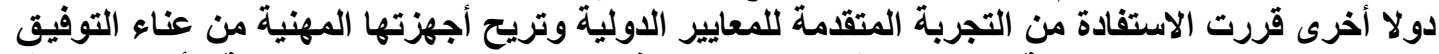

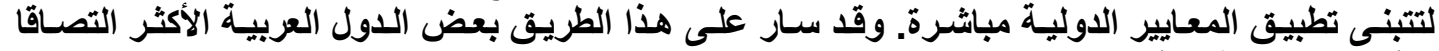

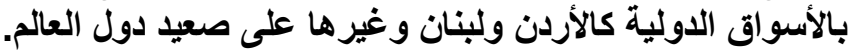

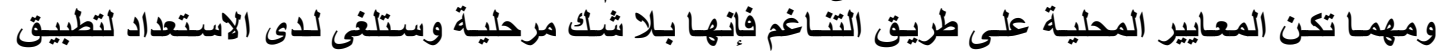

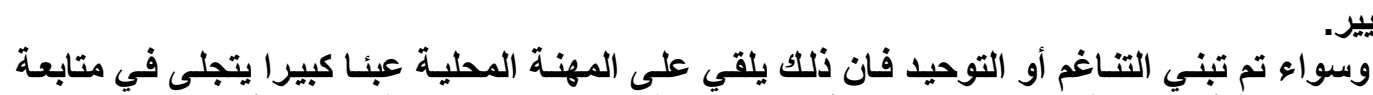

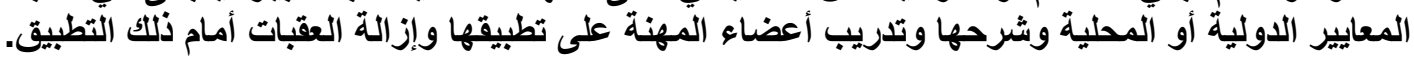

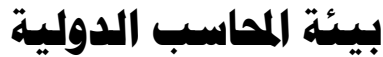

تتأثر المحاسبة الدولة بمجموعة من المؤثرات الداخلية والخارجية وهي كما يلي:

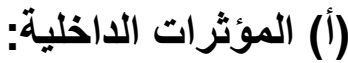

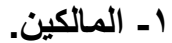

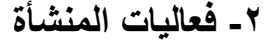

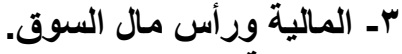

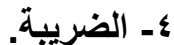
هـ الاحتراف المحاسبي. 7ـ الثقافة وبحوث المحأسبة.

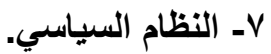

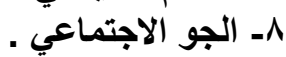
9ـ نمو وتطور الاقتّتصاد.

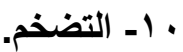
1ا 1- النظام القانوني. r ا ا ـ النظام المطبق. با 1 آ- المجتمع. ع اـ العوامل الدولية. 


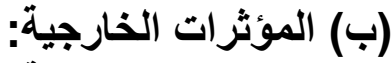

1- إ- العوامل الاجتماعية.

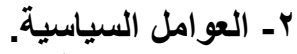

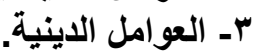

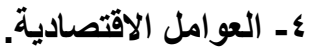

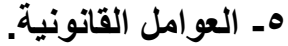

وهذه العو امل لها تأثير كبير على طبيعة وعمل النظام المحاسبي المتبع في تلكا الدولة، حيث يعكس

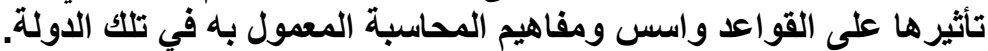

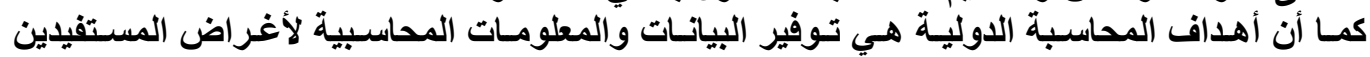
الخارجيين والاخاخليين وتمثل مستخدمي المطلومات والبيانات الداخلية هم:-

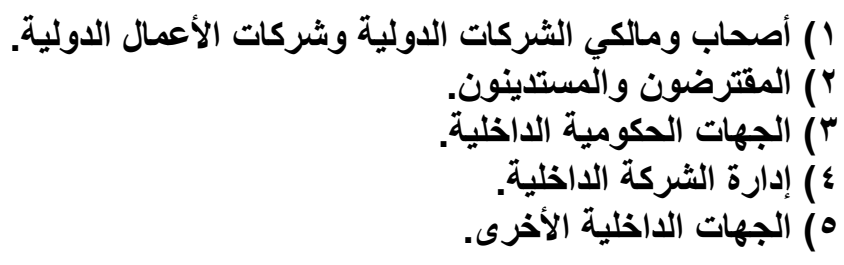

كما تتأثر الدحاسبة الدولية بالاجتهادات والاتجاهات بين المحاسبين وخضوع أمور محاسبية كثيرة

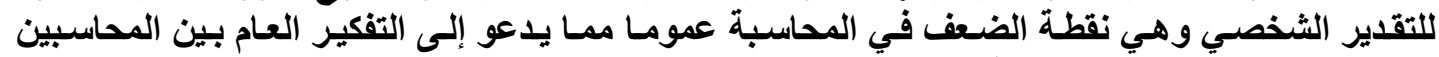

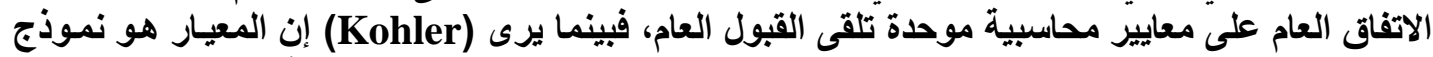

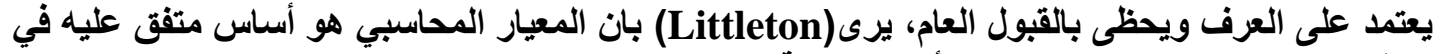
التطبيق المحاسبي السليم ويستخدم كأداة للمقارنة.

أسعار التحويل Transfer Pricing

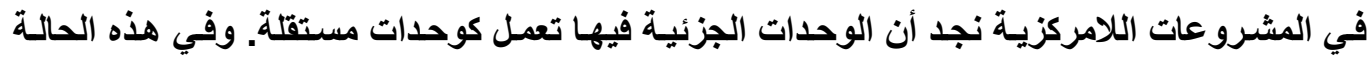
يستخدم نظام الرقابة الإدارية أسعار التحويل بتنسيق ولتنقييم الأداء في هذه التهات الوحدات الجزئية.

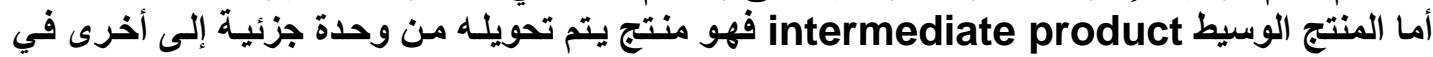

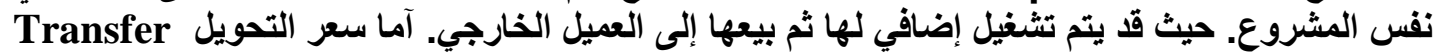

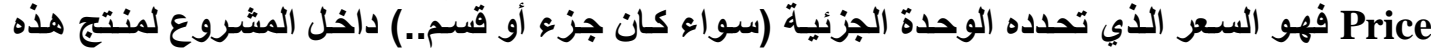

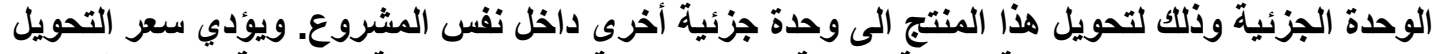

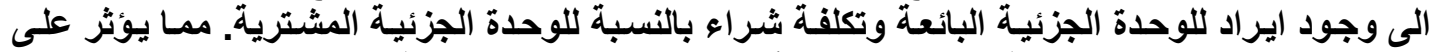
الاخل التشغيلي لكل وحدة جزئية وهو المقياس الأساسي لاداء كل وحده جزئية داخل المشروع.

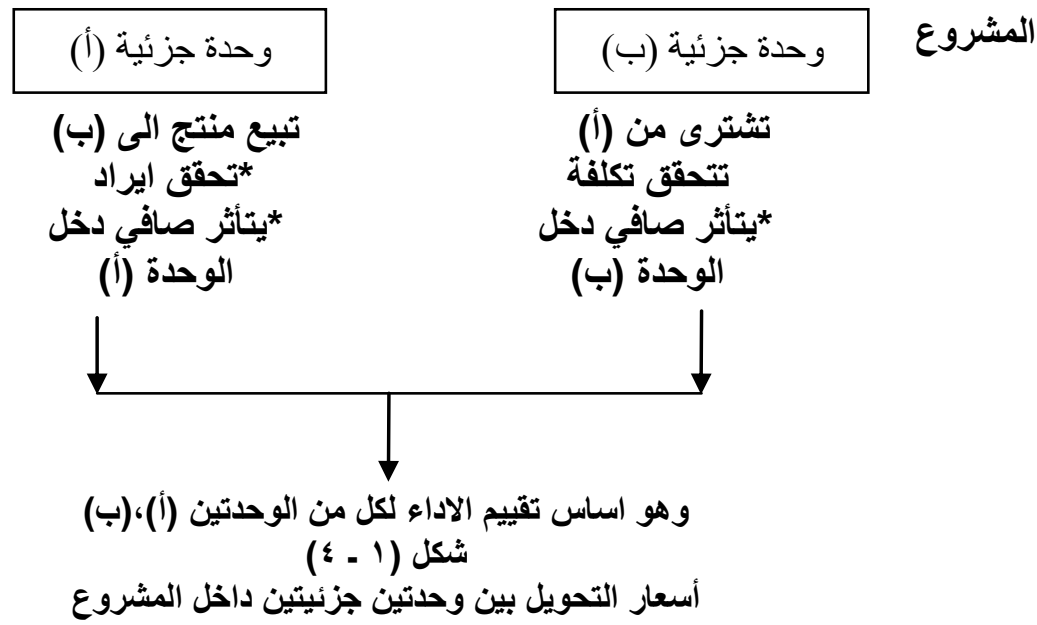

الطرق المختلفة لتسعير التحويل

توجد ب طرق عامة لتحديد سعر التحويل وهي: 1- أسعار تحويل مبنية على أسعار السوق. 
r- حيث قد تختار الإدارة العليا استخدام سعر نفس المنتج في السوق الخارجي.

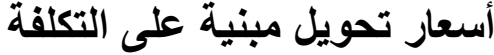

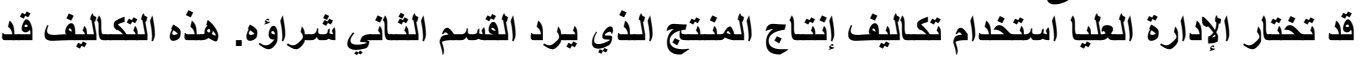

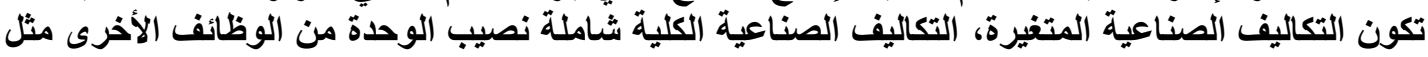

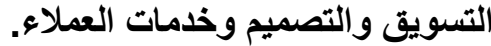
r- أسعار التحويل التفاوضية:

عندما تكون الأجزاء الجزئية بالمشروع لهُ لها حق المفاضلة بين شراء احتياجاتها من خـارج المشروع او

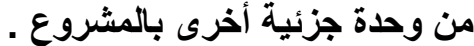

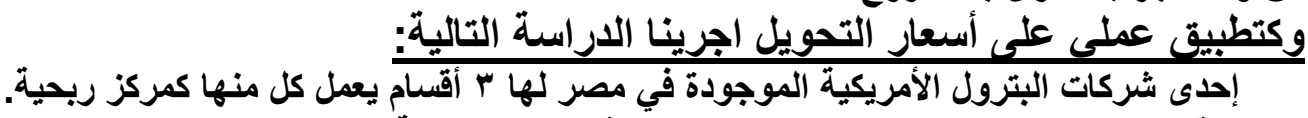

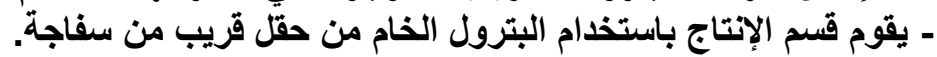

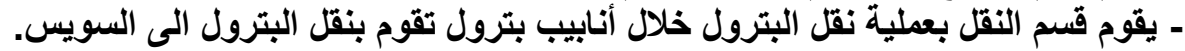

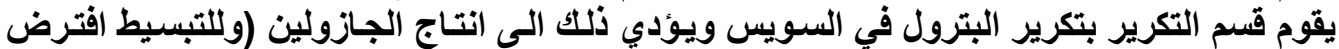
ان الجازولين هو المنتج الذي يمكن بيعه في قسم التكرير وان كل ب برميل من البترول الجئرل الخام ينتجان برميلا

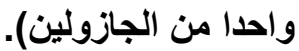
ومن المفترض أن تكون التكلفة المتغيرة لكل قسم متفيرة حسب تكلفة واحد كل قسم:

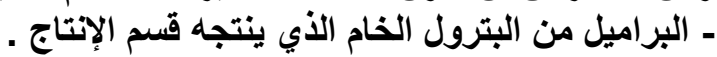

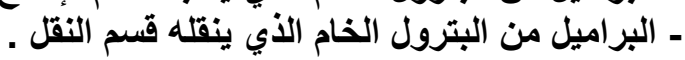

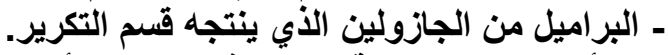

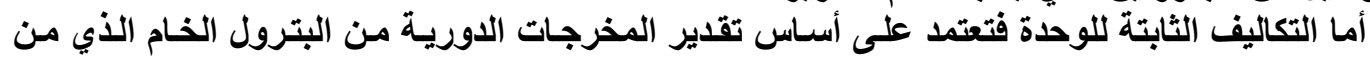

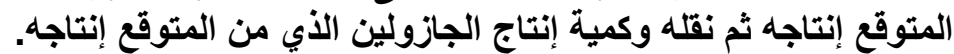

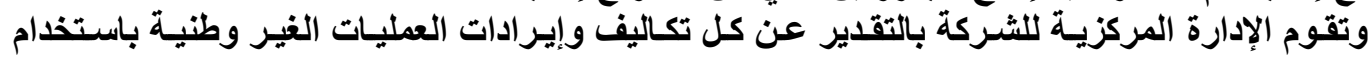

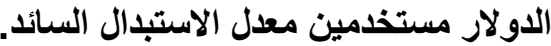

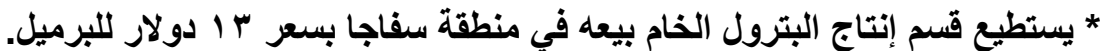

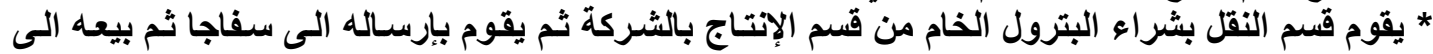
وتبلغ طاقة النقل في خط النقل الواحد من سفاجا الى السويس . . ., · ؛ برميل من البترول الخـام قسم التكريز.

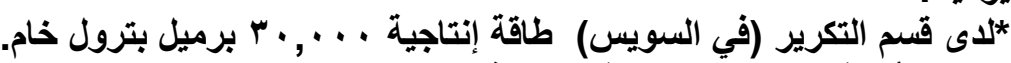

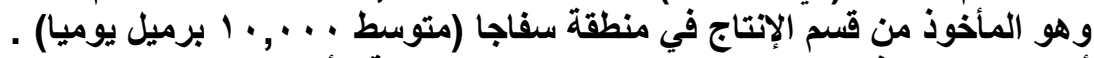

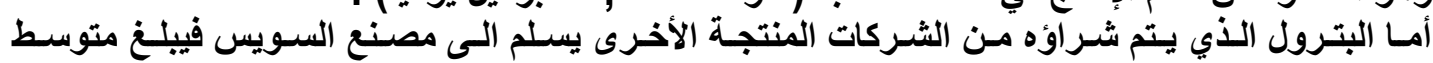

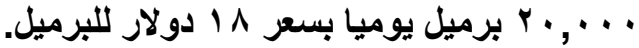

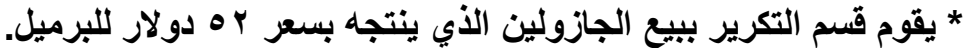

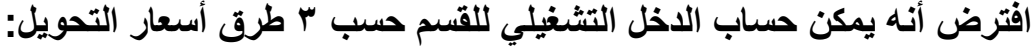

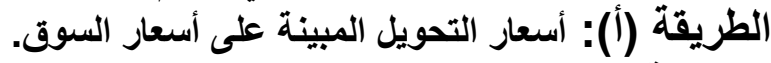

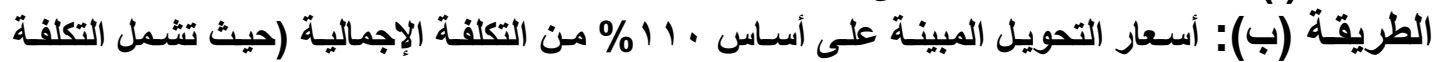
الإجمالية على تكلفة المنتج الذي تم الحصول عليه بالإضافة الى التكاليف المتغيرة والثابتة للقسم). الطريقة (ج): أسعار التحويل التفاوضية.

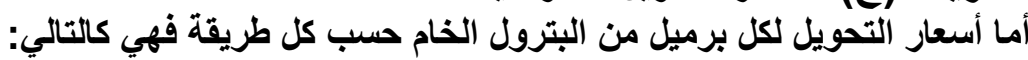

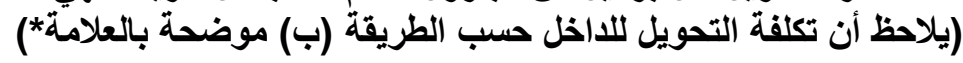




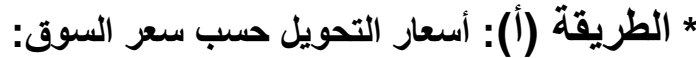

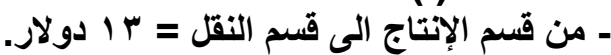

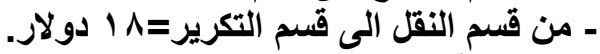

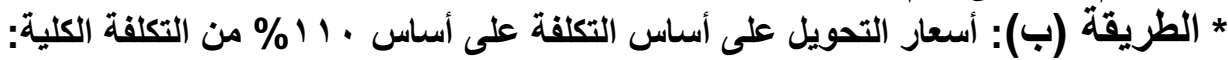

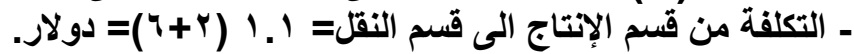

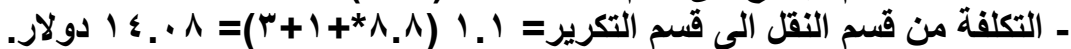

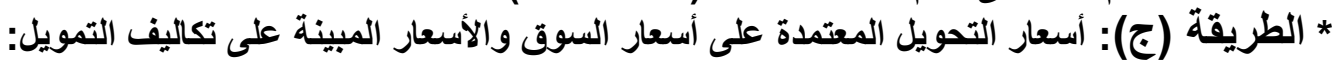

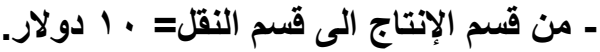

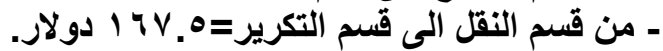

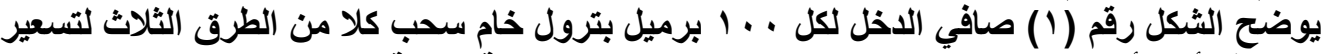

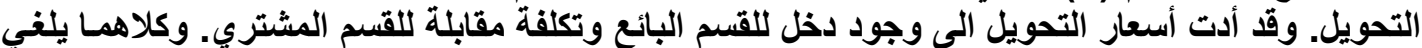

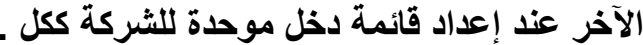

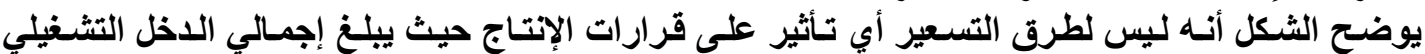

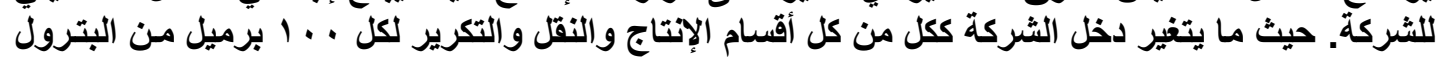

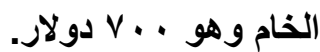

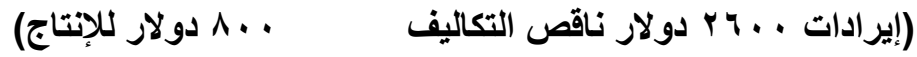

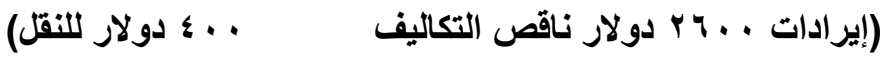

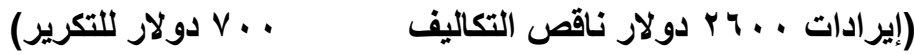

وذللك بغض النظر عن طريقة أسعار التحويل المستخدمة. ويوضح بقاء صافي دخل الثركة كما هو أنتا نريد جذب النب الانتباه نحو تثأثير طرق أسعار التحويل على الدخل

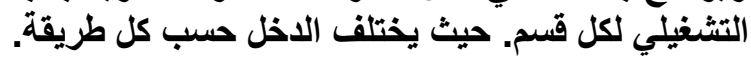

حيث يبلغ الاخل التشغيلي · r ع دولار في قسم الإنتاج.

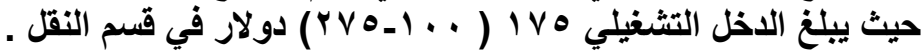

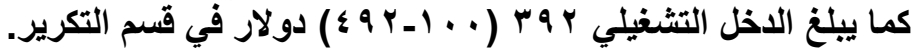

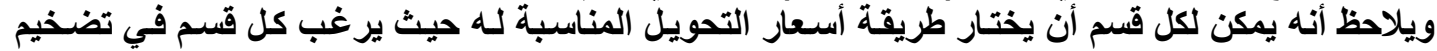
أرباحه وعلى ذلك فسوف يختار قسم الإتتاج أسعار السوق، بينما يختار قسم التحويل طريقة التهار التفاوض

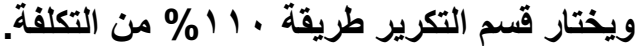

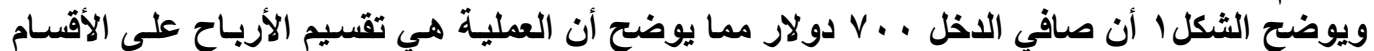

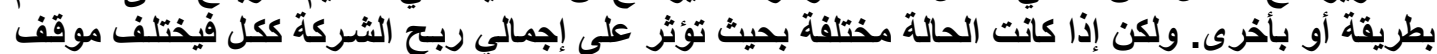

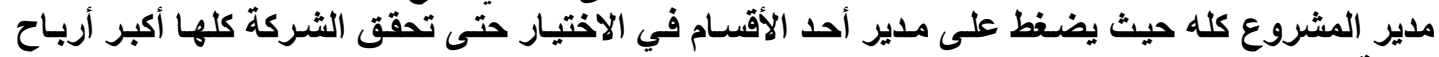


شكل (1)

بيانات شركة البترول

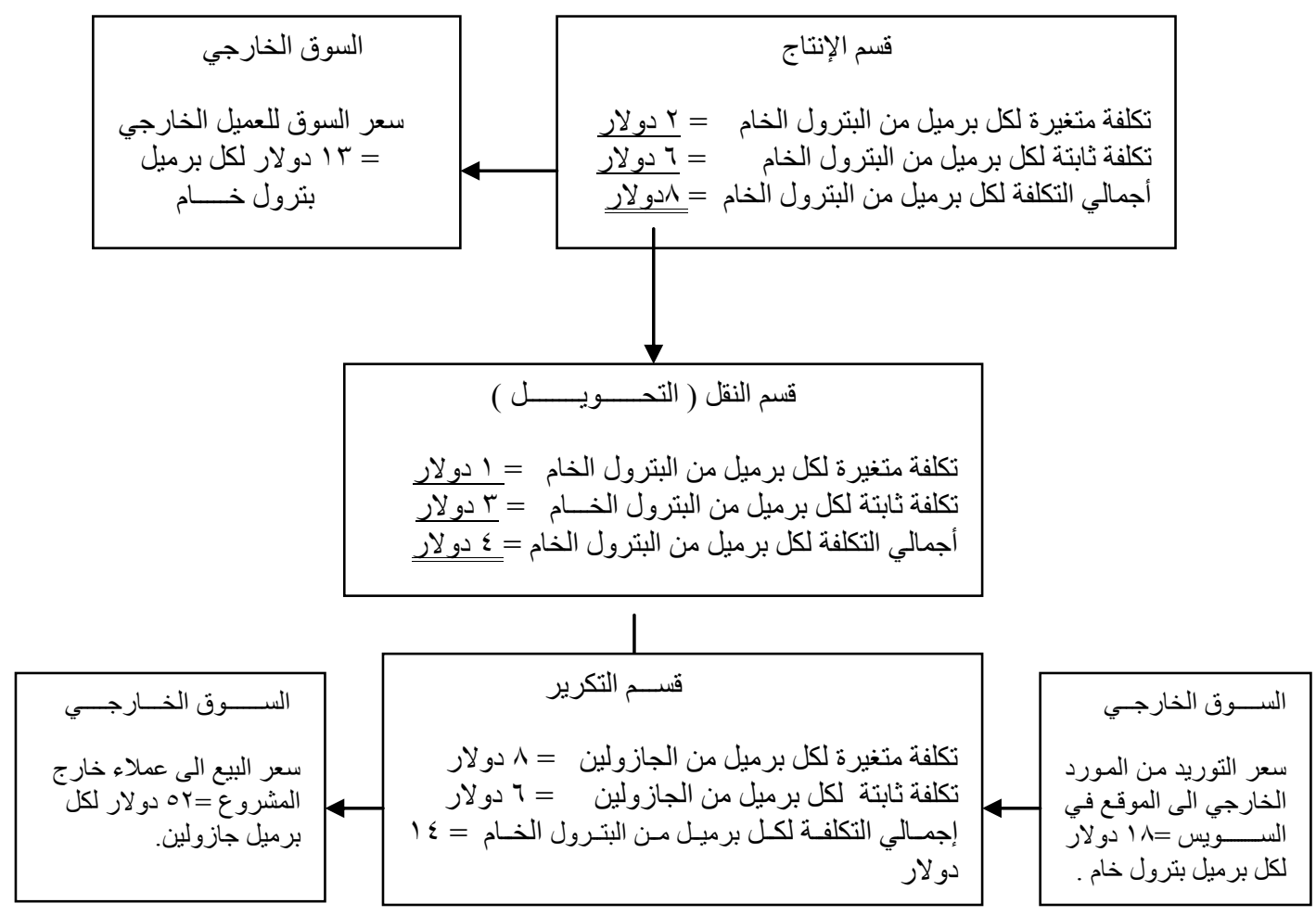

الطريقة (أ) الطريقة (ب) الطريقة (ج)

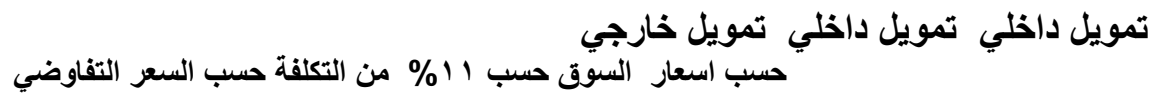

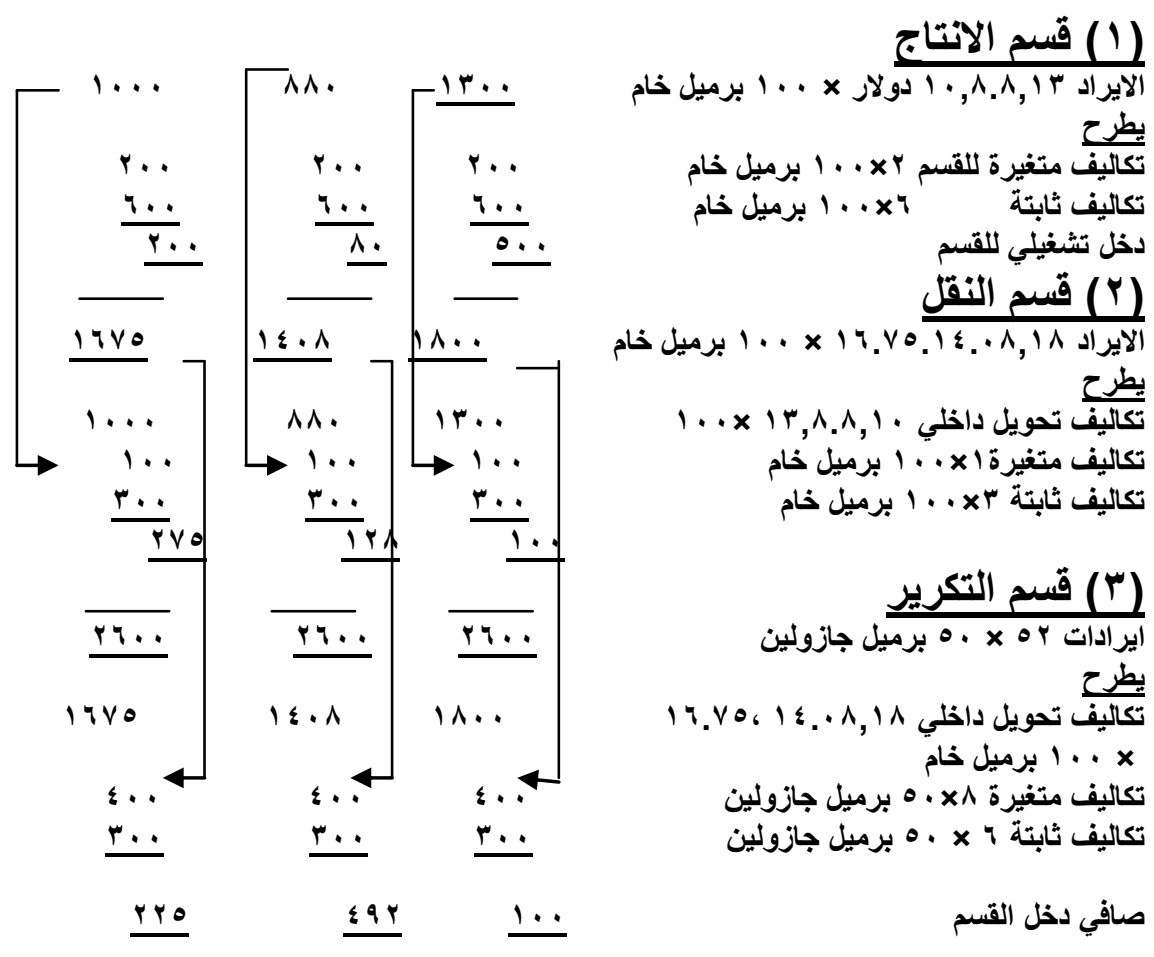




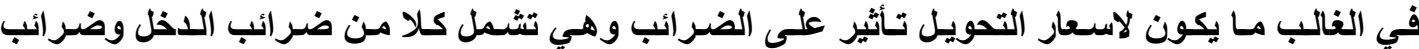

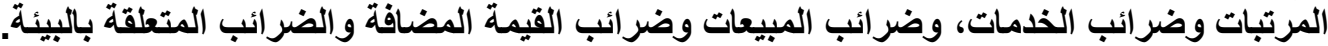
ويهدف الجزء التالي الى توضيح عوامل الضريبة خاصة ضريبة الاخل لاعتبار هام في قرارات استعار

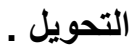

افترض بيانات شركة البترول السابق إيضاحها بالثكل (1)

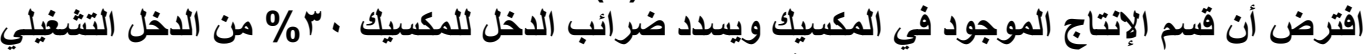

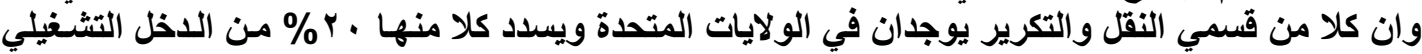
وتهذف الثركة الى تقليل إجمالي تسديدات ضرائب الاخل. وذلكت باستخدام طريقة ـ 11\% من طريقة كالضرائب التكلفة الإجمالية لتسعير التحويل، كما يتضح من الجدول فيدالت التالي:

\begin{tabular}{|c|c|c|c|c|c|c|}
\hline \multicolumn{3}{|c|}{ ضر ائب الدخل على · · 1 برميل من البترول الخام } & \multicolumn{4}{|c|}{ الدخل التشغيلي لـــ • • ب برميل من البترول الخام } \\
\hline 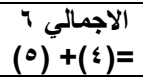 & 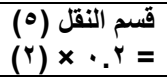 & 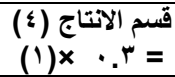 & الاجمالي & $\begin{array}{c}\text { قسم النقل } \\
\text { (Y) }\end{array}$ & $\begin{array}{c}\text { قسم الانتاج } \\
\text { (1) }\end{array}$ & طريقة تسعير \\
\hline 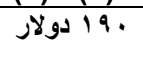 & - · - دولار & 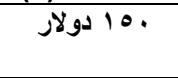 & دولار & دولار & دولار & 1- طريقة السوق \\
\hline $1 \leqslant \Lambda$ & TY & $Y \varepsilon$ & $v_{\cdots}$ & Tr. & A. & آ- اجمالي التكلقة 11 من \\
\hline 19. & $1 \cdots$ & 7. & V.. & $0 \ldots$ & r.. & r- السعر التفاوضي \\
\hline
\end{tabular}

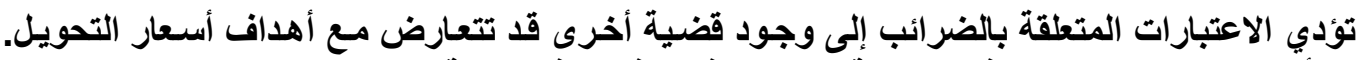

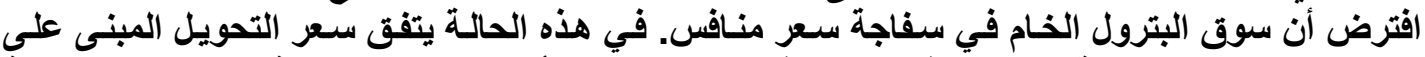

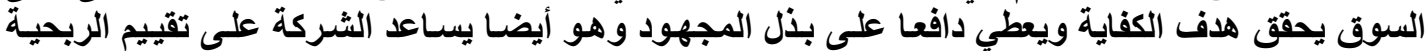

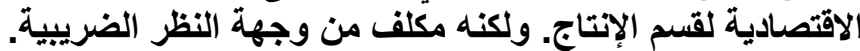

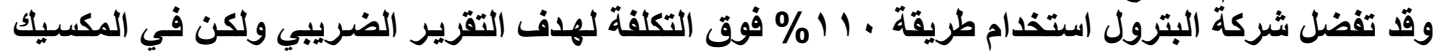

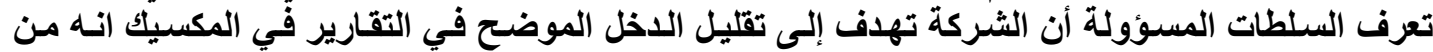

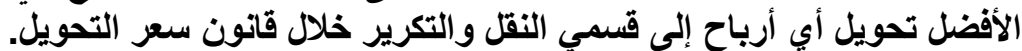

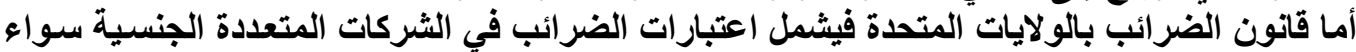

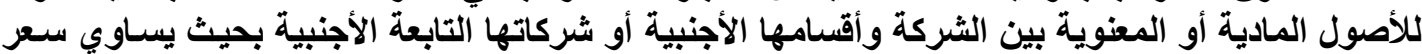

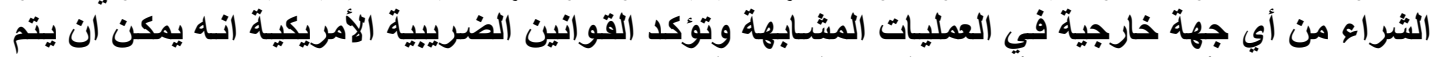

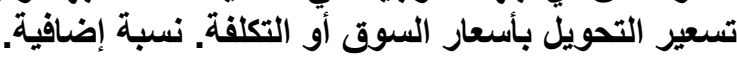

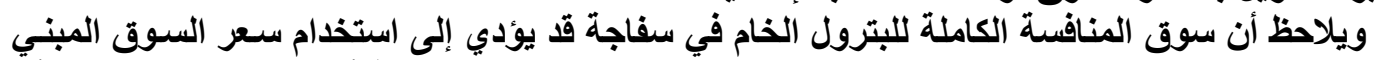

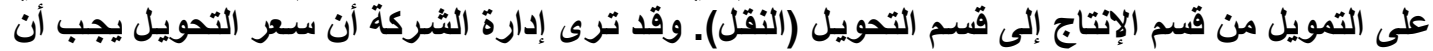

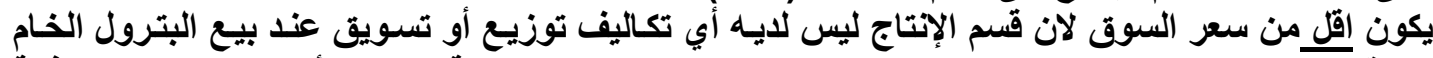

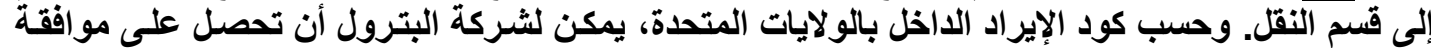

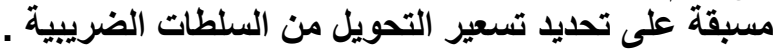




\section{المهور الثاني/ العولمة المعاصرة: تعريفها اثارها. هؤسساتها}

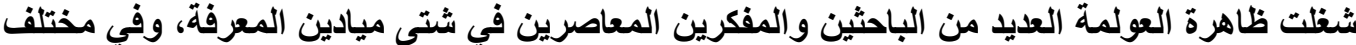

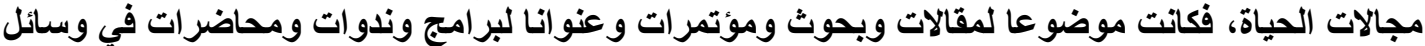

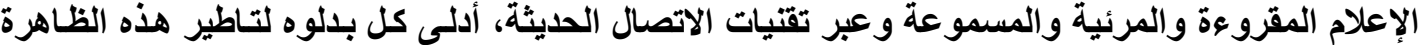

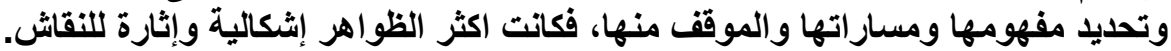

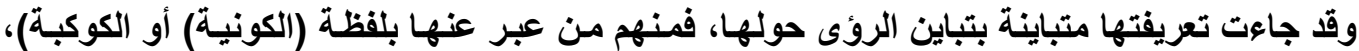

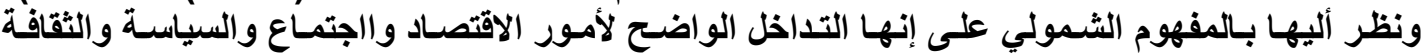

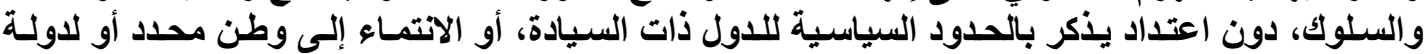

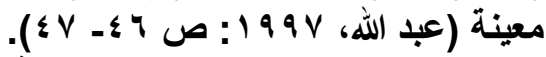

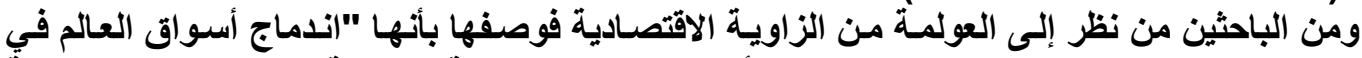

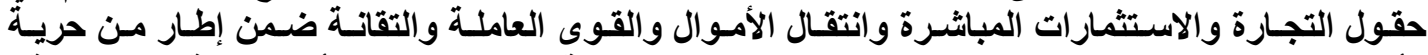

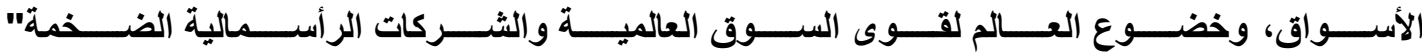

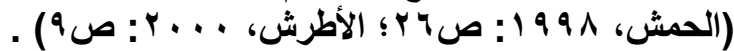

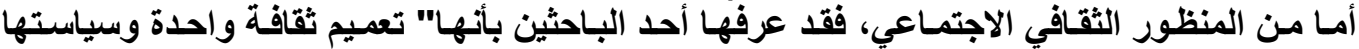

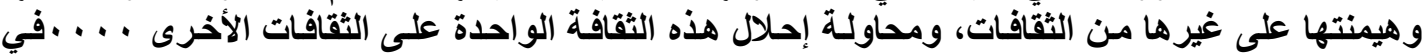

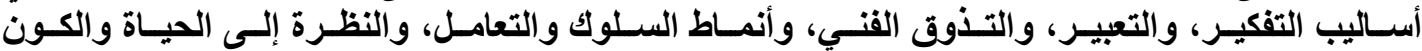

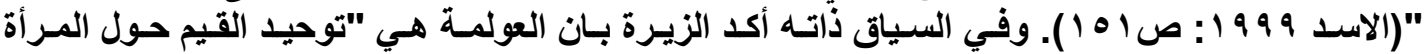

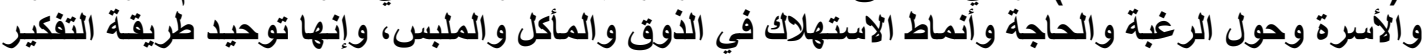

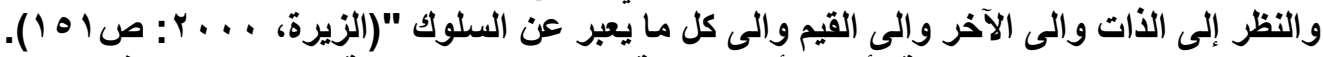

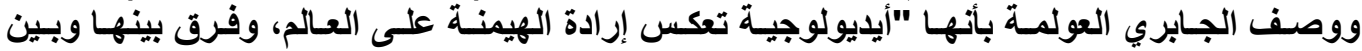

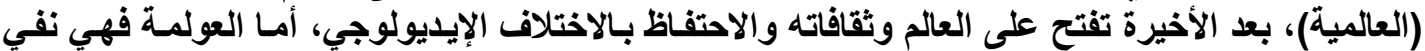

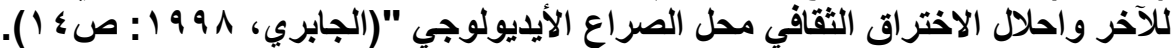

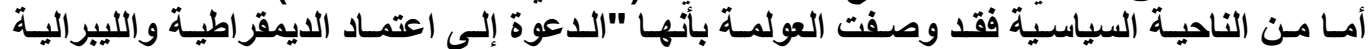

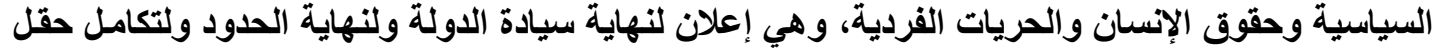

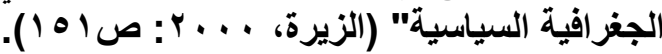

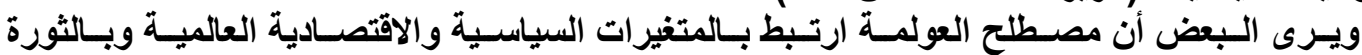

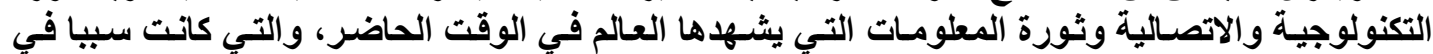

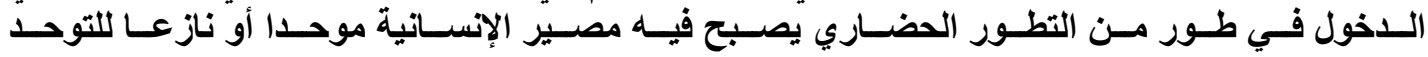

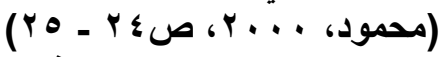

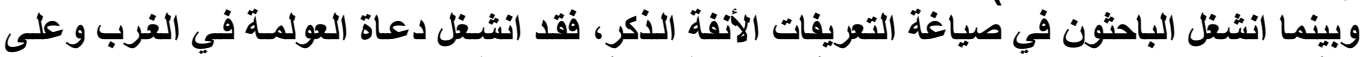

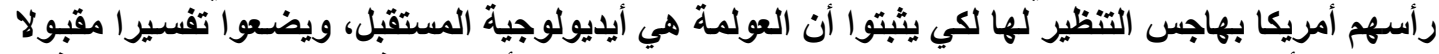

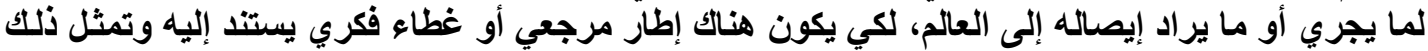

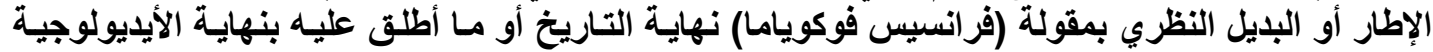

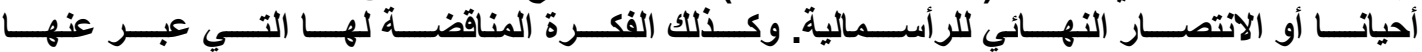

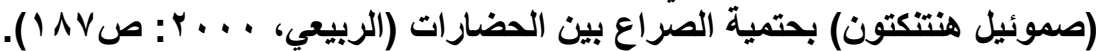

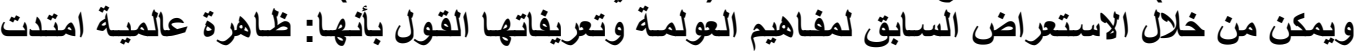

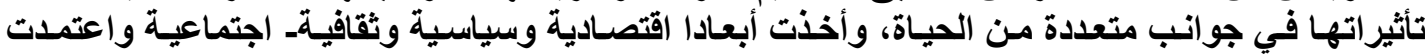

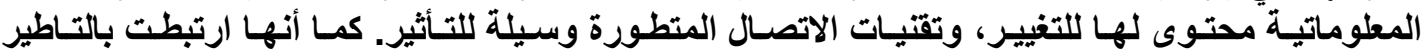

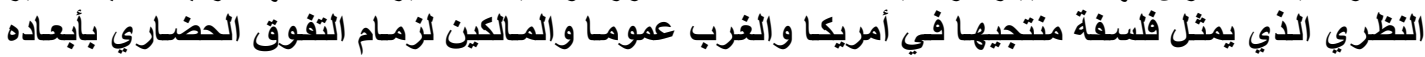

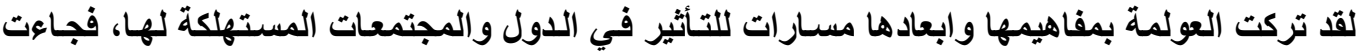

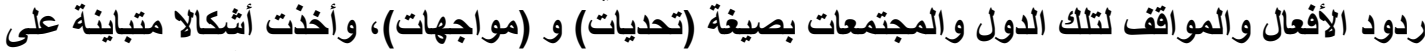

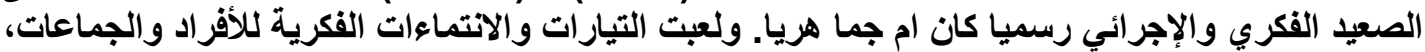

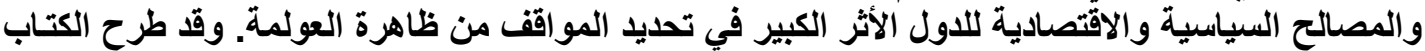

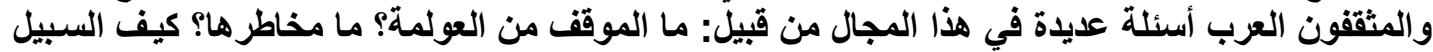

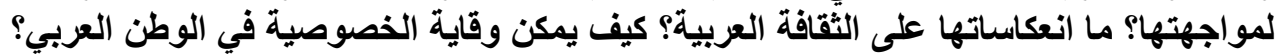

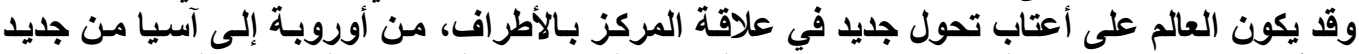

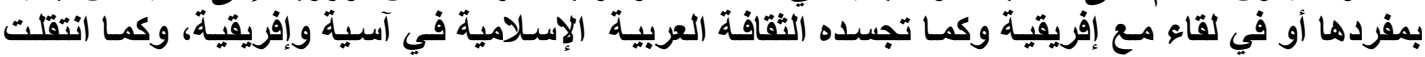


الروح من الثرق إلى الغرب عبر آلاف السنين، فقد تعود الروح مـن الغرب إلى الشرق من جليد الثرايد في

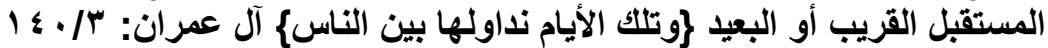

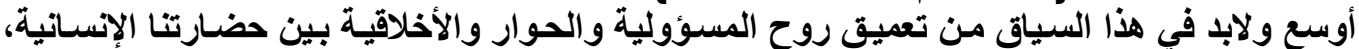

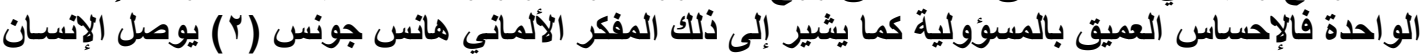

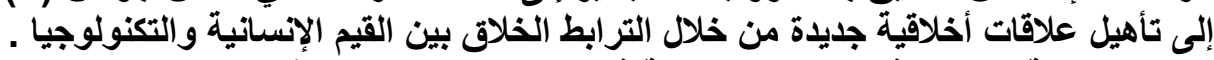

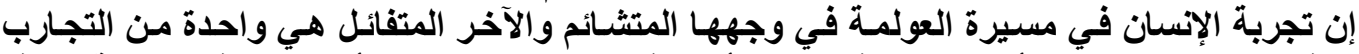

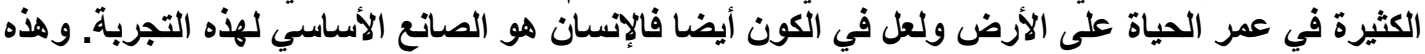

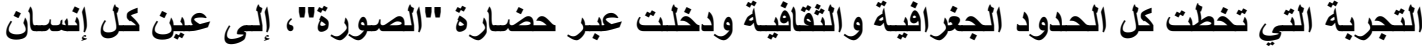

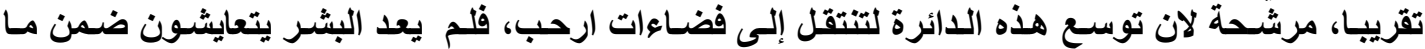

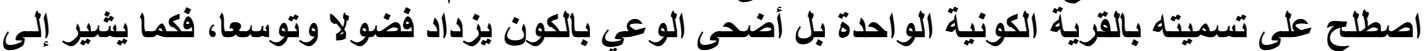

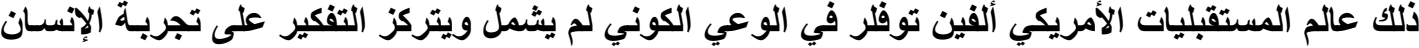

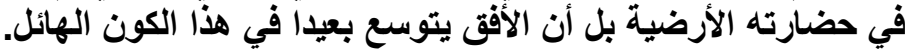

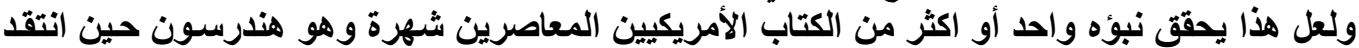

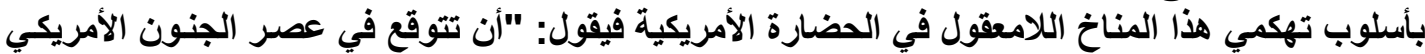

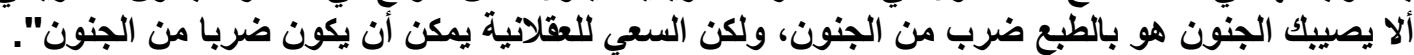

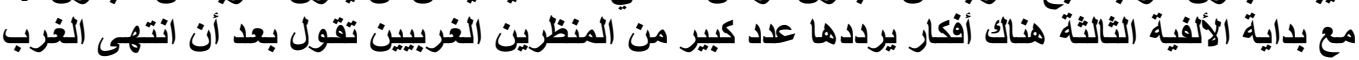

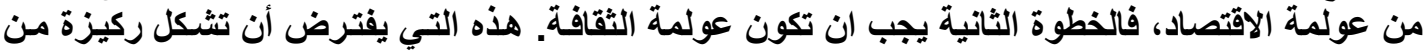

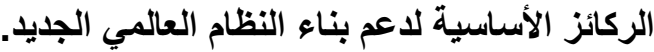

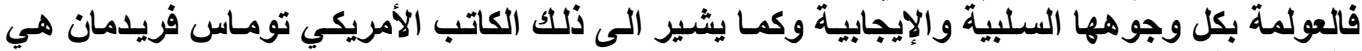

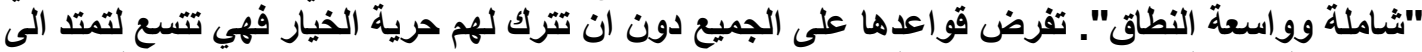

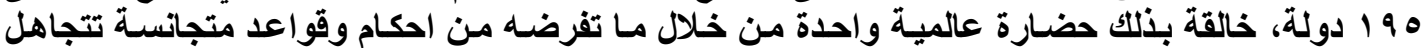

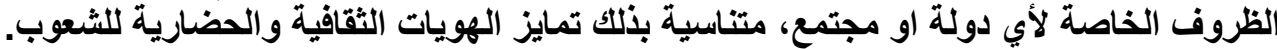

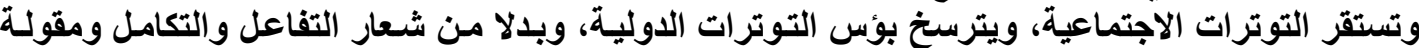

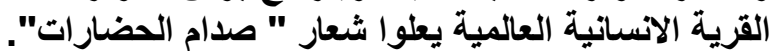

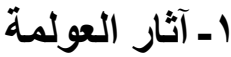

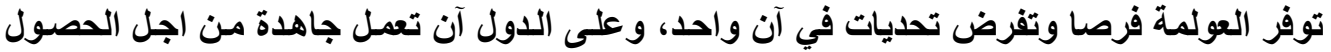

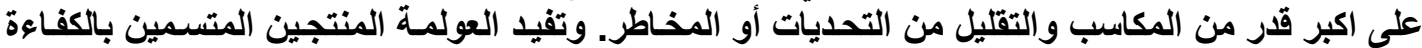

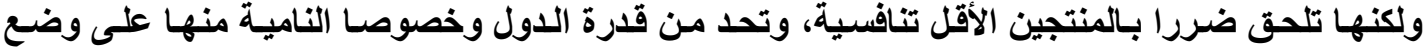

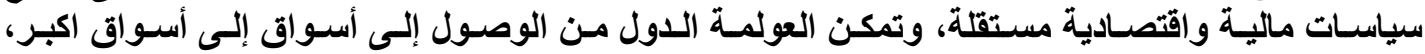

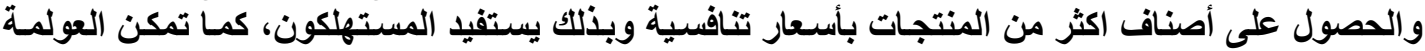

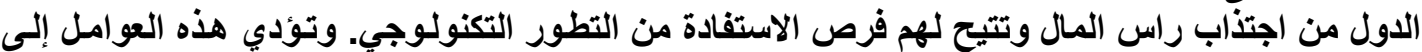

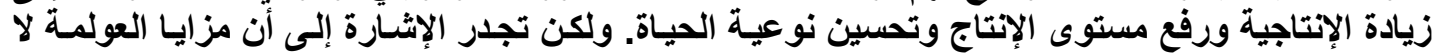

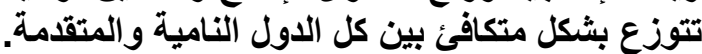

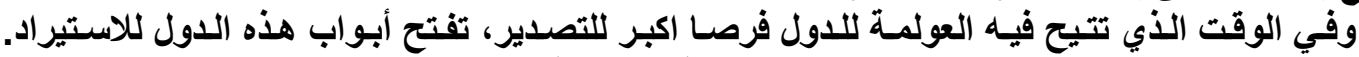

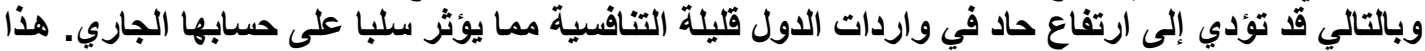

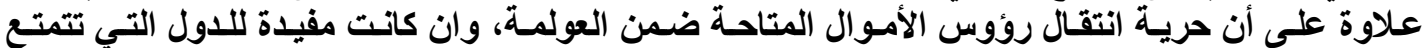

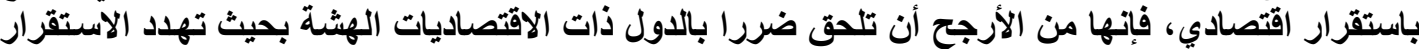

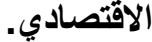

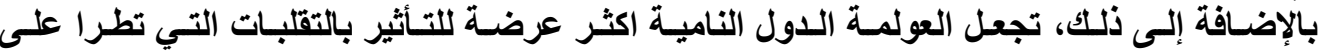

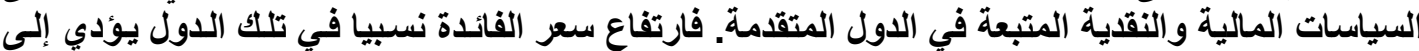

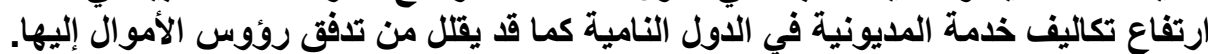

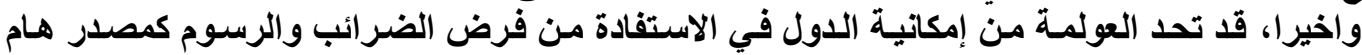

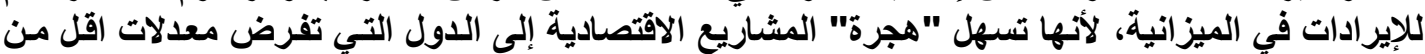

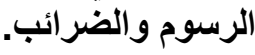

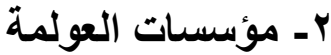 هناك ثلاث مؤسسات كبرى دولية تقوم بإرساء قوات العد ويناء هيكل العولمة وهي:

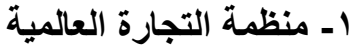 r - ـ صندوق النقد الدولي} بـ البنكك الدولي، وهي تثثرف على تكوين البنيـة التحتية الأساسية العولمـة، حيث تسعى لجعل الاقتصـاد 
العالمي اكثر انفتاحا، واكثر ترابطا، واكثر استقرارا وانضباطا متجاوزة في ذلتك الحدود السياسية للدول.

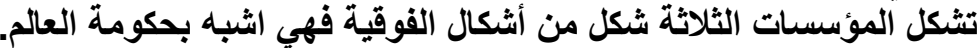

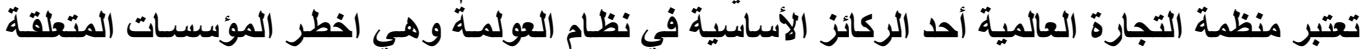

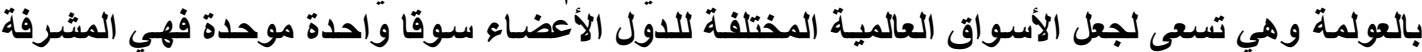

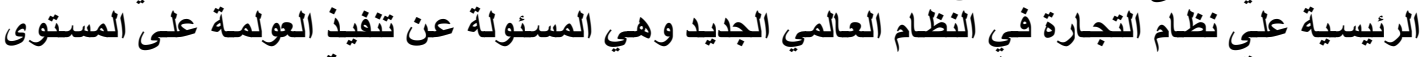

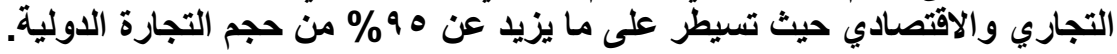

ومن اجل حماية المنافسة فان منظمة التجارة العالمية تقوم بمكافحة الممارسات التجارية غير العادلة

r ـ الإغراق- قيام بعض المضئ المصدرين بتخفيض أسعار السلع والخدمات المصدرة عن الأسعار المحلية. r- إز الإلة كافة الحواجز الجمركية التي تقف أمام حركة التجارة.

الجدير ذكره هنا أن الولايات المتحدة الأمريكية والاتحاد الأوروبي تسيطران سيطرة شبها تامة على هذي هذه

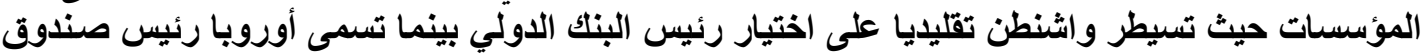

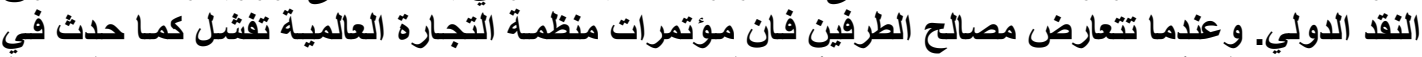

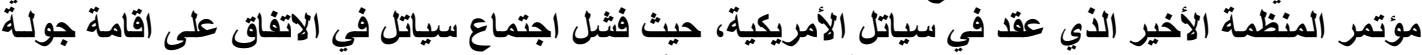

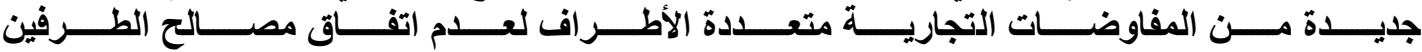

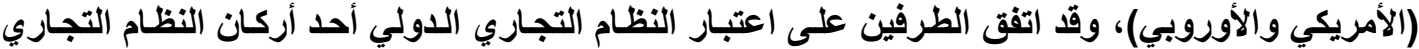

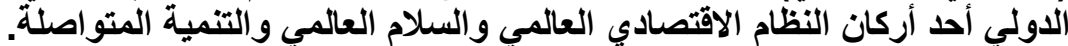

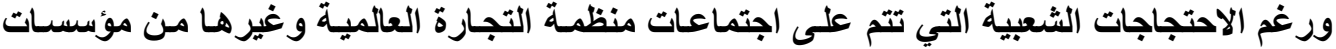

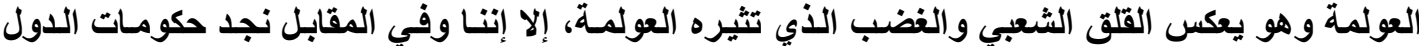

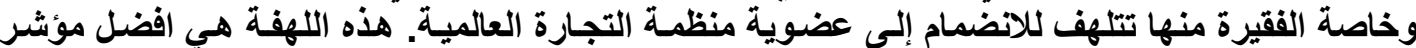
لاعم العولمة من قبل حكومات منات الدول الفقيرة.

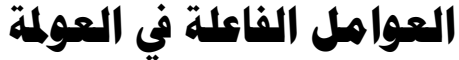

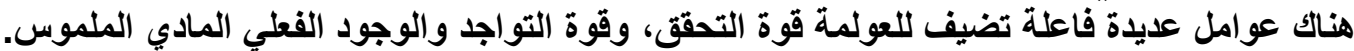

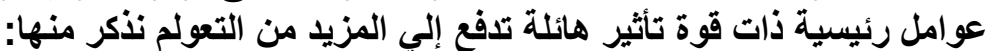

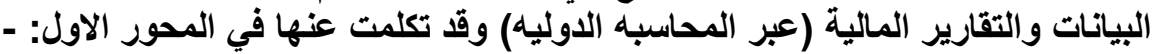
ـ ـ شبكة المعلومات الأولية (الإنترنت).

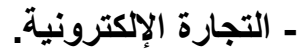
ـ - مبكة الاتصالات العالمية. ـ ـ التفطية الإعلامية الكونية العبة (المحطات القضائية) ـ - المنظمات غير الحكومية.

الإنترنت: ليست الإنترنت سوى جهاز راديو متنقل يمكن أن يستخدمه الهواة فيمـا بينهه. الرأي السـائد

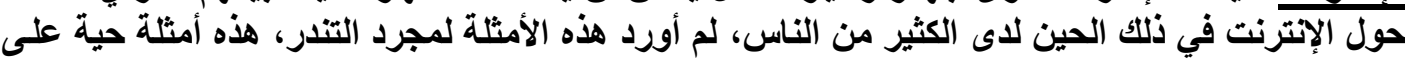

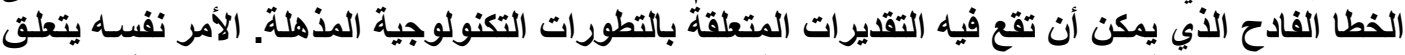

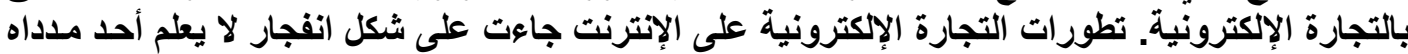

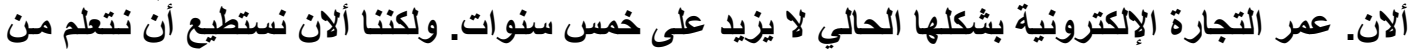

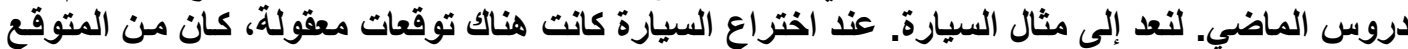

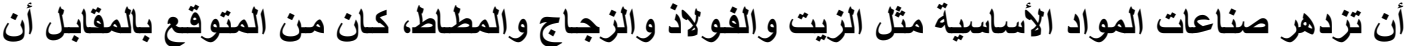

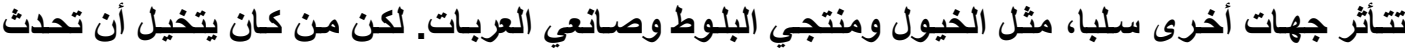

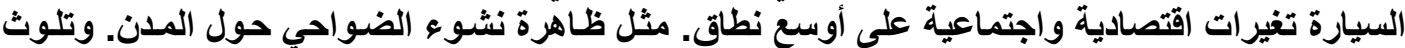

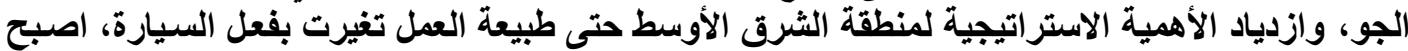

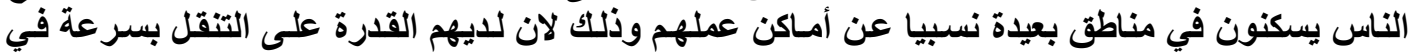

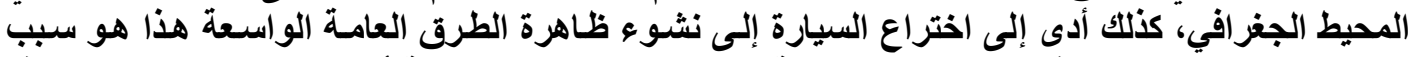

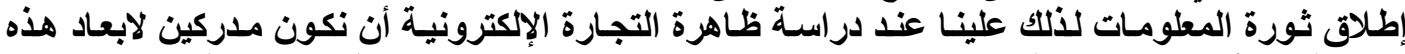

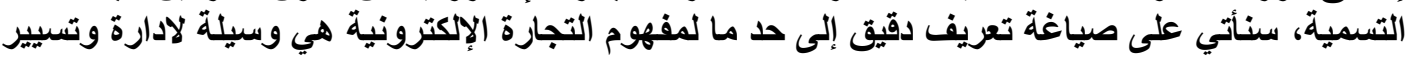




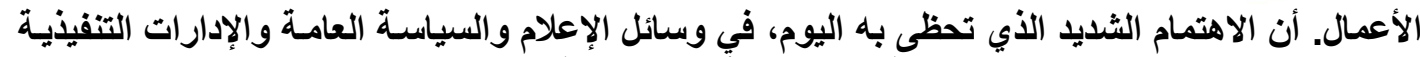

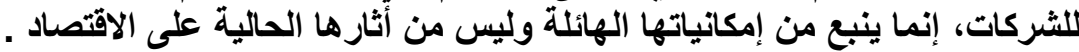

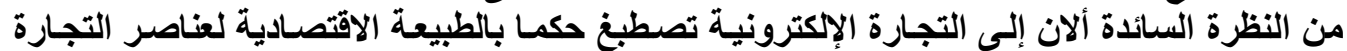

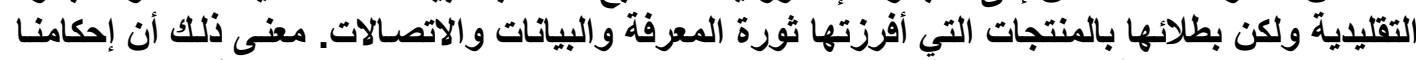

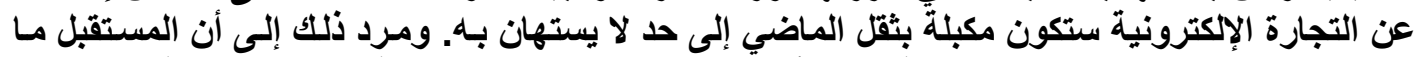

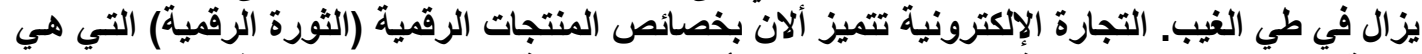

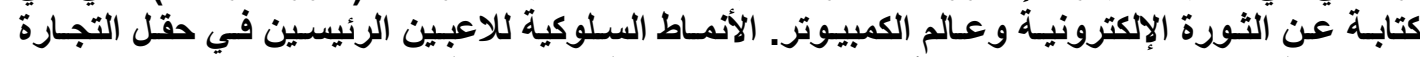

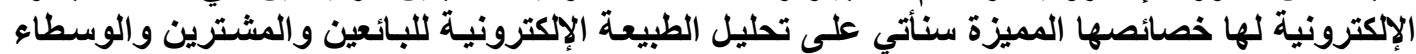

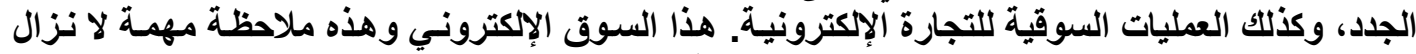

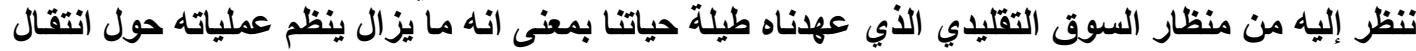

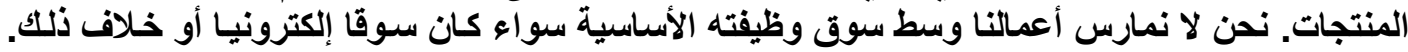

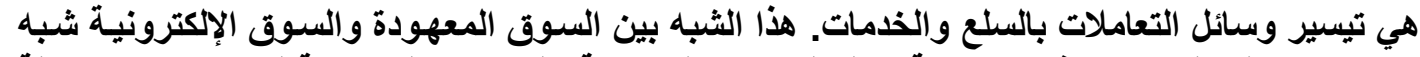

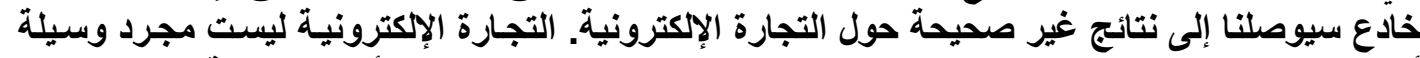

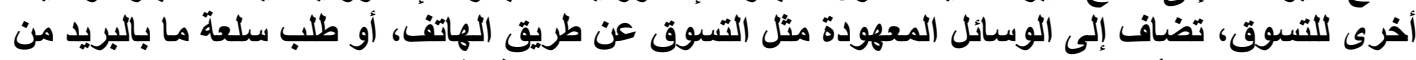

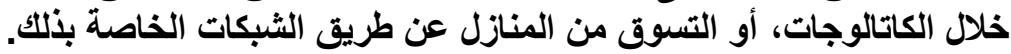




\section{المهور الثالث/ فاعلية التجارة الإلكترونية في العولمة}

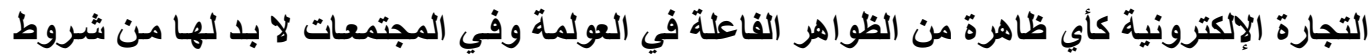

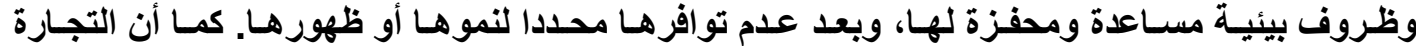

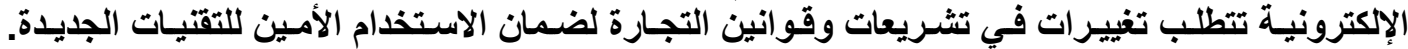

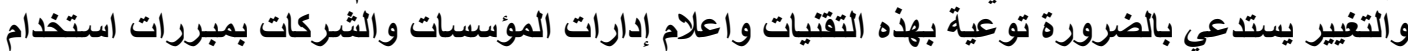

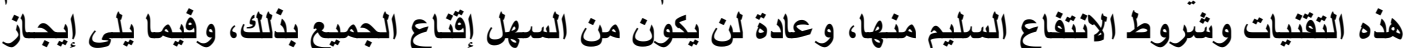
لاهم المحددات المحتملة أمام ظاهرة التجارة التمارة الإكترونية:أولا: المحددات التقتية تعتمد التجارة الإكترونية على الاستخدام الكفي لثبكات الإنترنت، وهي بذلك تتطلب:

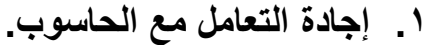

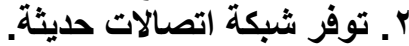

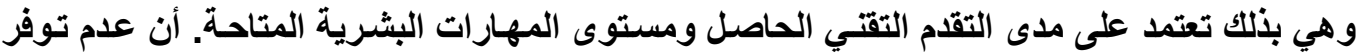
بنية تحتية معلوماتية وطنية هو أحد المحددات الأساسية للانتفاع من تقنيات التجارة الإلكترية الكترونية .

$$
\text { ثانيا: المحددات المالية والقانونية }
$$

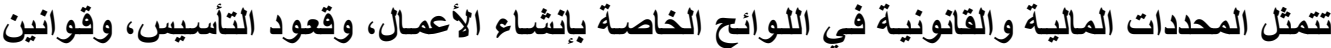

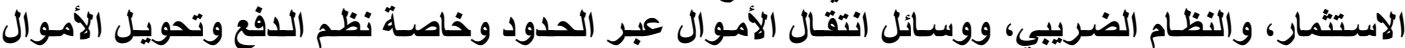
بالوسائل الإكترونية الإنية ثالثا: المحددات الأمنية الأبية

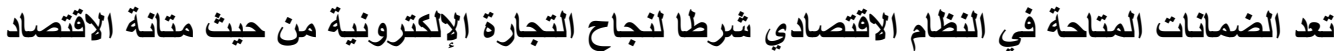

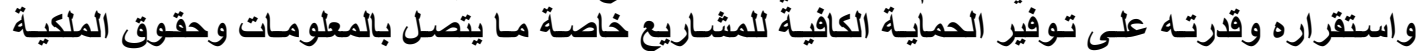

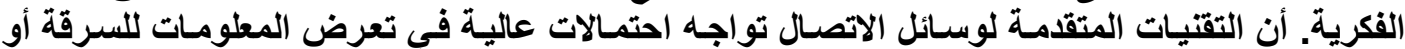

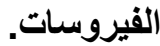
رابعا: المحددات السلوكية تعد الخصائص الثخصية والنمط الثقافي للمستهليك والأطراف الأخرى المستخدمة لتقنيات التجارة الإكترونية من العوامل الجوهرية لمدى كفاءة الاستخدام وفاعليته.

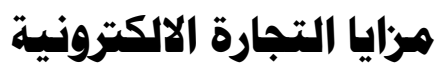

توفر التجارة الإلكترونية مزايا عديدة ومتنوعة سواء للشركات أو العملاء أو المنتجين والمستهلكين

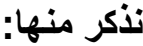

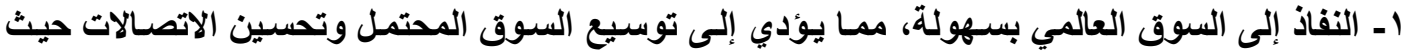

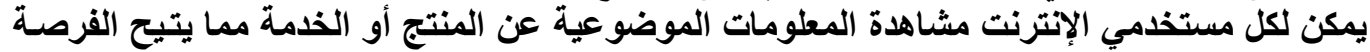

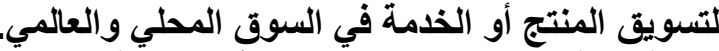

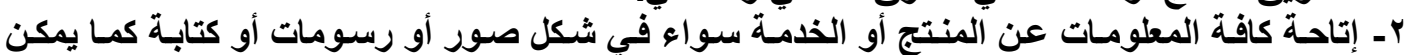

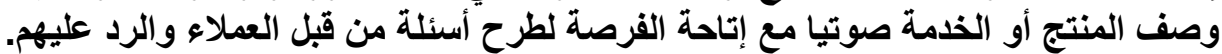

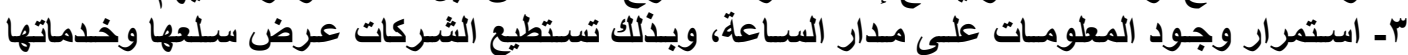

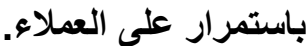
ع ـ تضائل الوقت والتكلفة عن السلعة أو الخدمة، نتيجة لذفض تكاليف إجراء الاتصالات وعقد الصفقات 


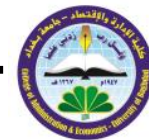

هذه المزايا لا تتحقق بإون تحديات نذكر بعضا منهيا

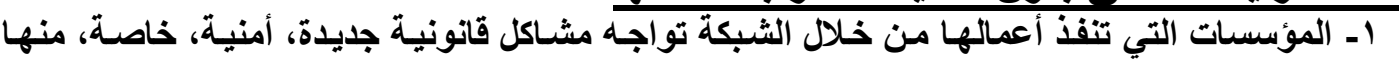

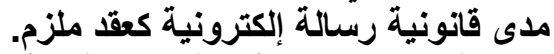

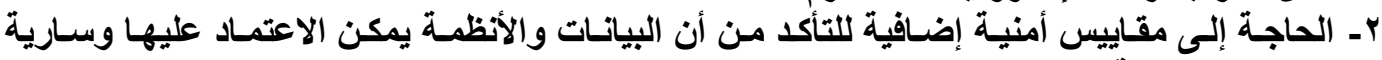
المفعول والحاجة إلى تطوير ها باستمرار.

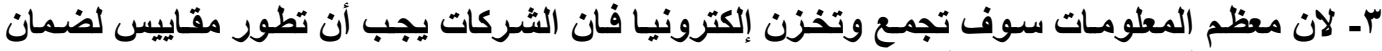
الخصوصية لزبائنهم وللثركة.

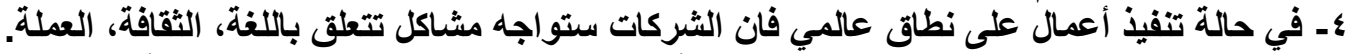

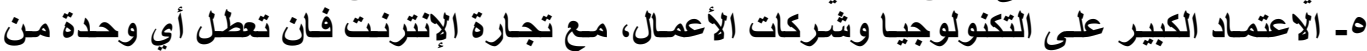
وحدات الثبكة يعني تعطل الأعمال.

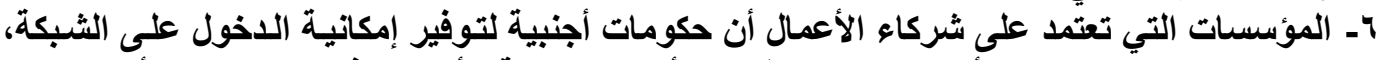

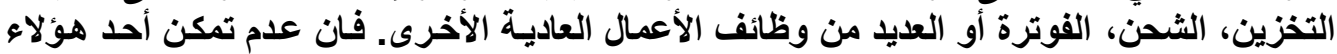

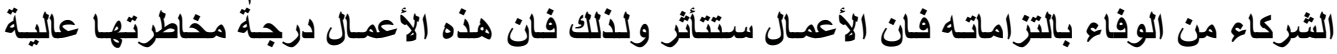

خصوصا للشركات الصغيرة نتائج اختبار الفرضيات

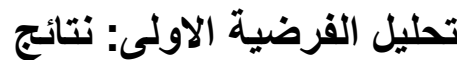

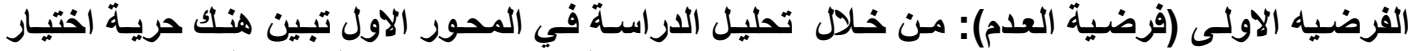

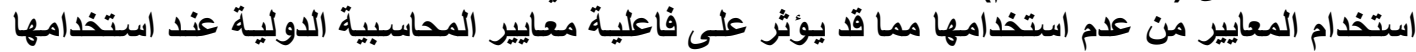
في بيئة العولمة. وكما يلي.

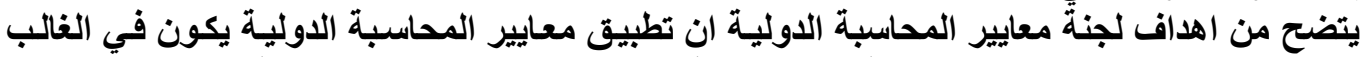

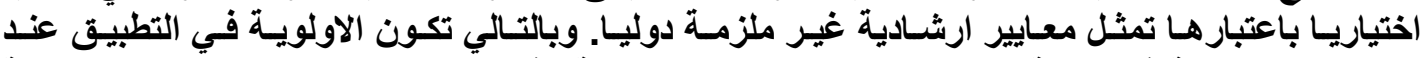

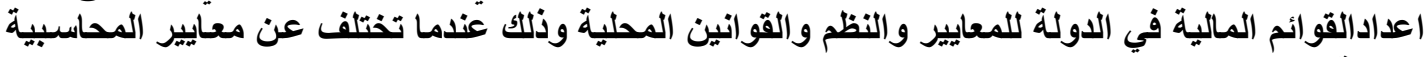

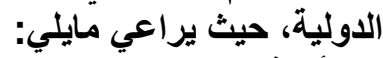
(أ) إذا كاتت المعايير المطبقة في القطر اقل من المعايير الذي اقرها الاتحاد الدولي تطبق معايير الاتحساد

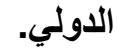
(ب) إذا كانت المعايير المطبقة في القطر اكثر واشد قوة من المعايير المحاسبية الدولية تطبق معايير

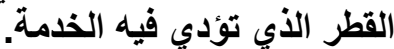

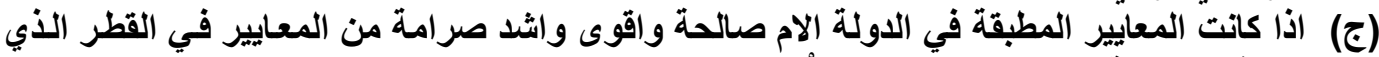
تؤدي فيه الخدمة تطبق معايير القطر الأم. الأمير تحليل الفرضية الثانية: نتائج الفرضيه الثانيه (فرضية العزية العدم):

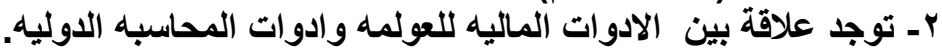

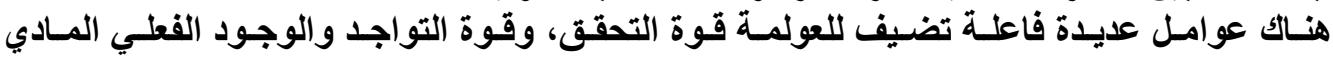

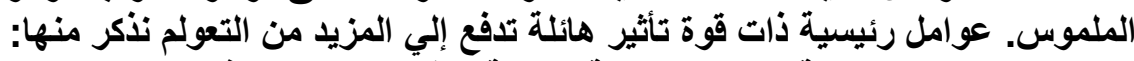

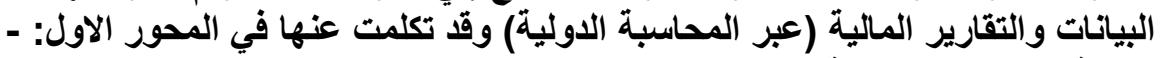

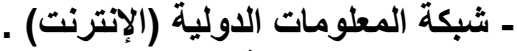

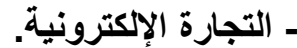
ـ ـ ـ ـبكة الاتصالات العالمية. ـ ـ التغطية الإعلامية الكونية (المحطات المية القضائية).

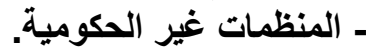

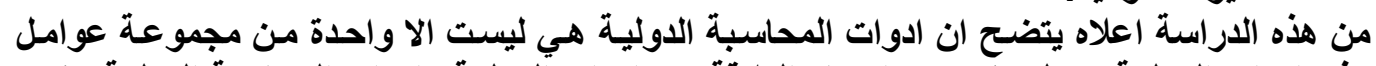

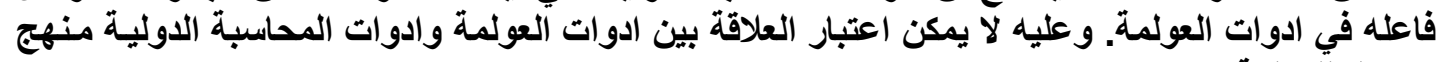


نتائج تحليل الفرضية الثالثه: (فرضية العلام)

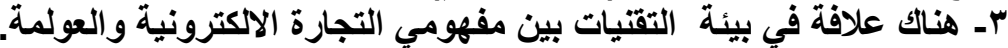

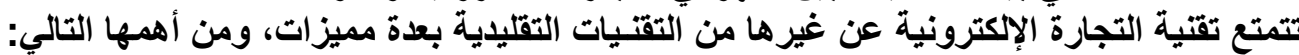

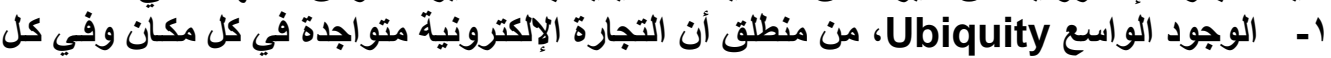

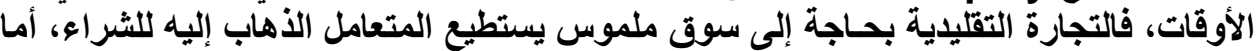

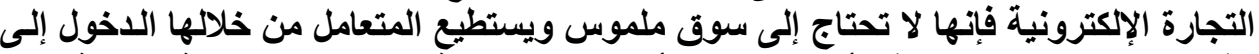

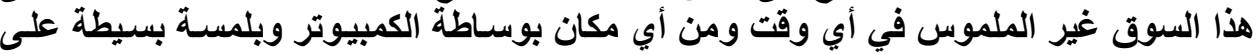

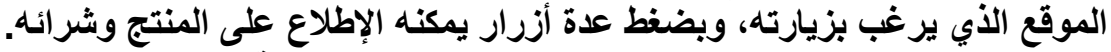

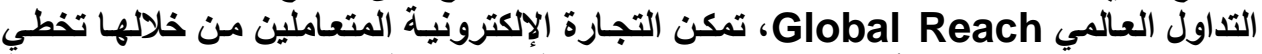

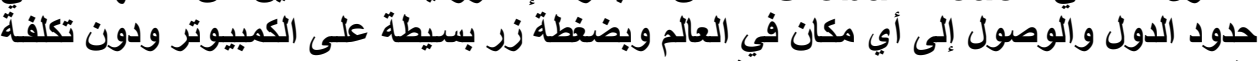

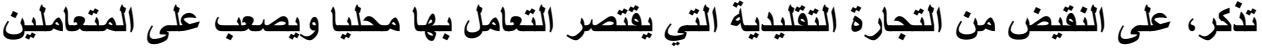

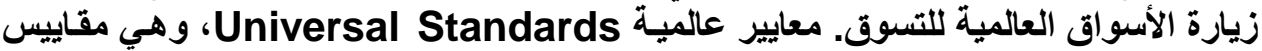

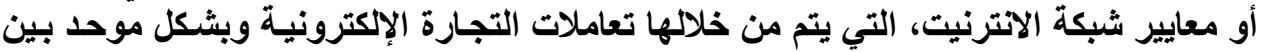

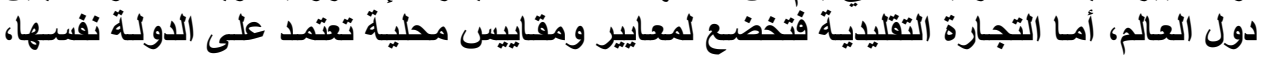

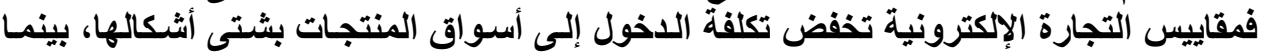
مقاييس التجارة التقليدية خاضعة لسياسات الدول وتكلفة دخول أسواق تلك الداول التول تختلف من دولة إلى أخرى . مئل

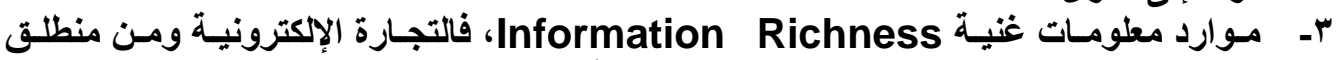

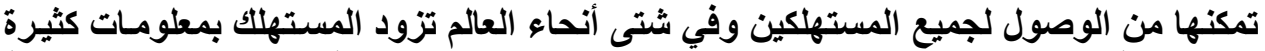

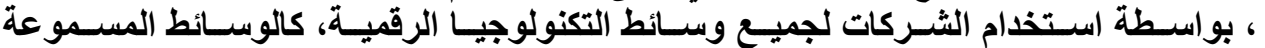

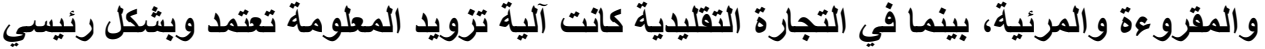

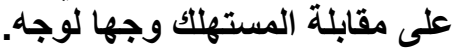

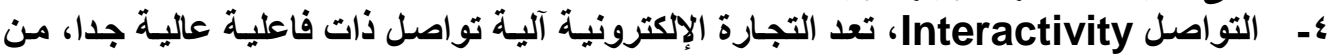

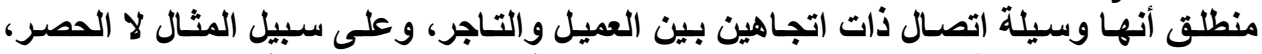

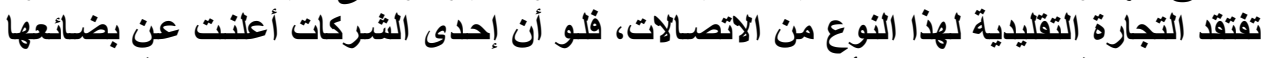

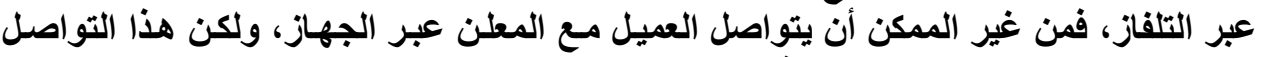
اصبح ممكنا عبر التجارة الإكترونية.

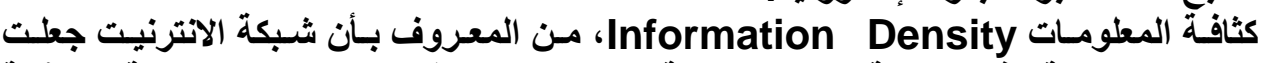

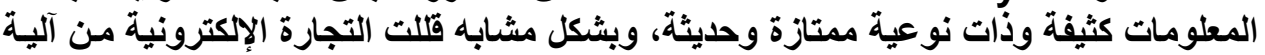

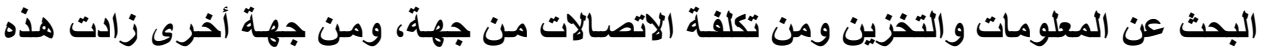

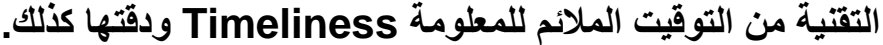

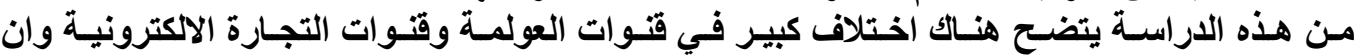

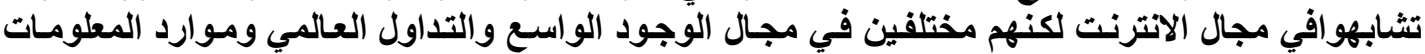

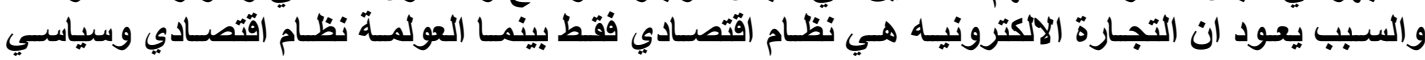




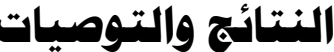

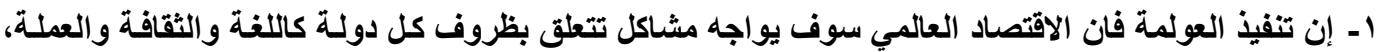

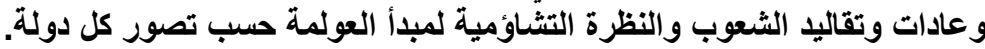

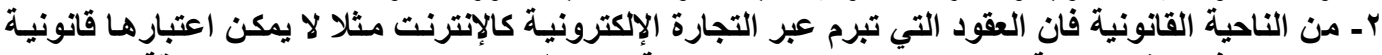

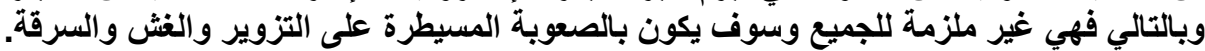

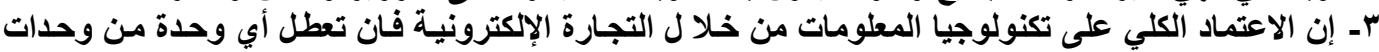

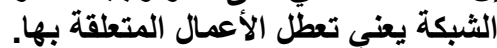

ع - إن تطبيق المعايير المحاسبية الدولية في كل الثيلية الثركات في العالم سوف يقليل الكثير من الفروق المحاسبية وبالتالي القضاء على مشكلة تنوع التبائي التبيق المحاسبي في التعالم.

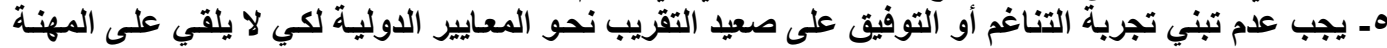

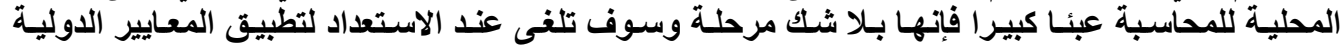

مباشرة.

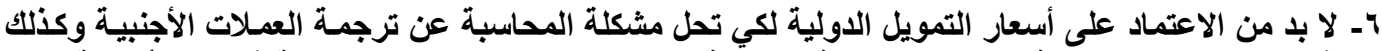
فان إعداد القو ائم المالية الموحدة للثركة القابضة والتية التئ تقع بعض شركاتها التابعة في دول أجنبية تمثل

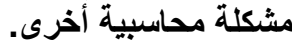

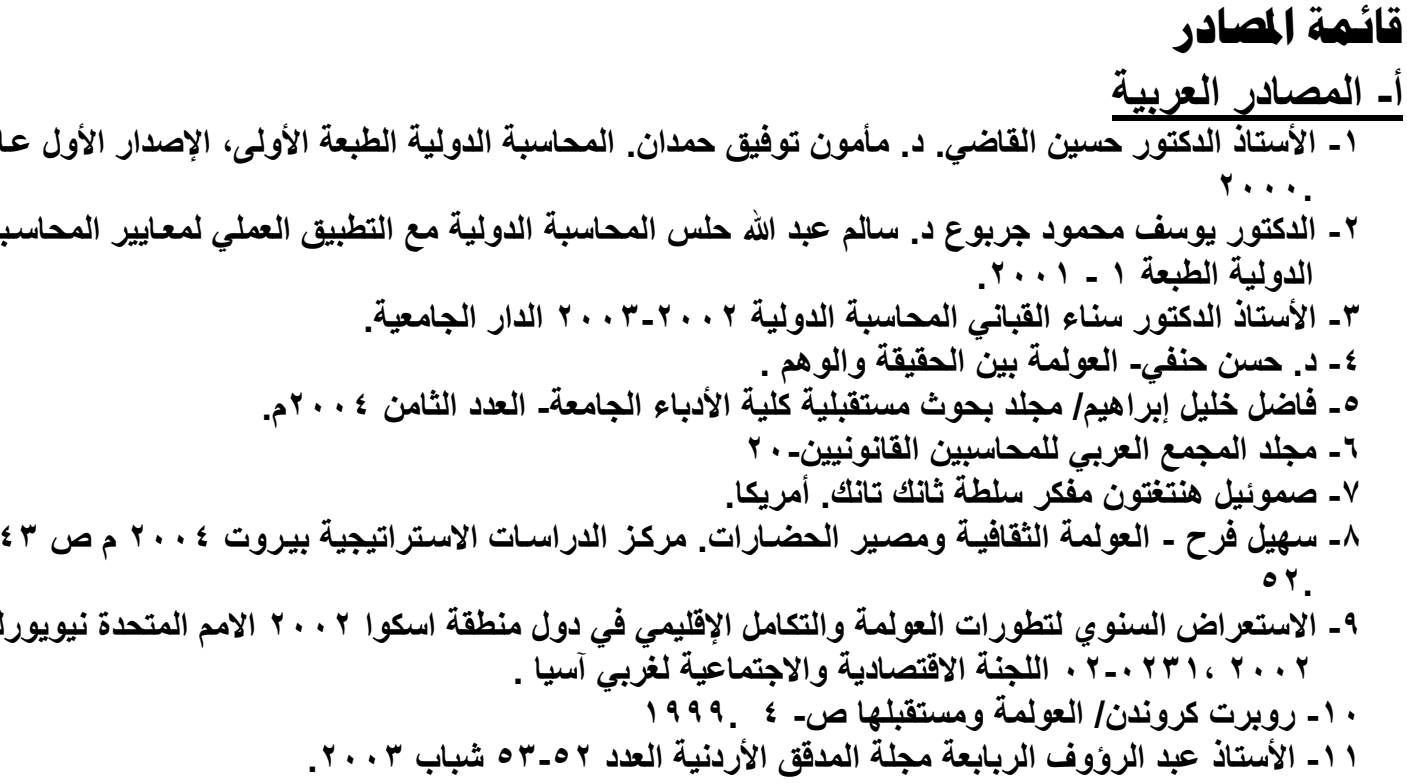

بـ المصادر الأجنبية

1-Mohamed A.E1-Erian, Globalization and The Arab Economies .From marginalization To Integration.P.5 The Egyptian Center For Economic studies, july 1997.

2- Alfen to vler . 3- Mocsow 1996 p.521.

3- Thomas L. Fridman, New York Times, sept. 1997.

4- Uoir: Hons Jonas. Le prinipe de Responsabilitd, une Ethique pourla civilization Techndogique. ( paris, ed cerf,1992). 